\title{
Review
}

\section{Role and Clinical Utility of Cancer/Testis Antigens in Head and Neck Squamous Cell Carcinoma}

Sharon C. Wu ${ }^{1}$ and Karl Münger 2,*

1 Molecular Microbiology Program, Graduate School of Biomedical Sciences, Tufts University School of Medicine ; Sharon_c.wu@tufts.edu

2 Department of Developmental, Molecular, and Chemical Biology, Tufts University School of Medicine; karl.munger@tufts.edu

* Correspondence: karl.munger@tufts.edu

Received: date; Accepted: date; Published: date

Simple Summary: In this review, we discuss the roles of cancer/testis antigens in the germline and their contributions to oncogenic cellular processes. Specifically, we focus on their clinical utility in head and neck squamous cell carcinoma and consider how cancer/testis antigens differentially expressed in HPV-positive HNSCC contribute mechanistically to the genesis and clinical characteristics of these cancers.

\begin{abstract}
Cancer/testis (CT) antigens exhibit selective expression predominantly in immunoprivileged tissues in non-pathological contexts but are aberrantly expressed in diverse cancers. Because of their expression pattern, they have historically been attractive targets for immunotherapies. The investigation of mechanistic roles of $\mathrm{CT}$ antigens in promoting oncogenesis has historically been a prominent research question, and a growing number of studies implicate CT antigens in promoting almost all the hallmarks of cancer. This suggests that $\mathrm{CT}$ antigens may act as cancer drivers. CT antigens are expressed in head and neck squamous cell carcinomas, although their role in the pathogenesis, prognostication, and treatment for this family of cancers remains poorly studied. Given that $\mathrm{CT}$ antigens hold intriguing potential as therapeutic targets and as biomarkers for prognosis and therapeutic response and that they can provide novel insights into oncogenic mechanisms, their further study in the context of head and squamous cell carcinoma is warranted.
\end{abstract}

\section{Keywords: CT antigens, HNSCC, HPV}

\section{Introduction}

Head and neck squamous cell carcinoma (HNSCC), comprising cancers derived from the oral cavity, nasopharynx, oropharynx, hypopharynx, and larynx, accounted for 796,577 new cancer cases and 387,117 cancer-related deaths in 2020 worldwide [1,2]. While around one-third of patients present with early-stage disease and have a favorable prognosis with surgery or radiotherapy, the 5-year overall survival for advanced-stage disease is $\sim 50 \%$ and there is a relatively high risk of recurrence and distant metastasis, which is typically incurable [3-5]. Thus, there remains an exigent clinical need to improve the therapeutic arsenal against this disease. Major risk factors for HNSCC include tobacco usage, excess alcohol consumption, environmental pollution, and infections with oncogenic human papillomaviruses (HPVs) [1]. Clinically, HPV-positive HNSCCs exhibit a distinct clinical course compared to HPV-negative disease. In particular, patients with HPV-associated oropharyngeal cancers have improved prognosis compared to those with HPV-negative cancers due in part to enhanced responsiveness to chemo and radiotherapy [4]. However, morbidity and quality of life 
remain major issues for patients [1]. Head and neck cancer survivors have the second-highest suicide rate, surpassed only by pancreatic cancer, and are almost twice as likely to die from suicide compared to survivors of other cancers [6]. Long-term morbidities include dysphagia, xerostomia, ototoxicity, and trismus [7]. Given the motivation to alleviate treatment-associated morbidity and the realization that a subset of HPV-positive HNSCC patients has a poor prognosis, there is great research interest in identifying biomarkers to define subgroups by prognosis or likelihood of safe response to treatment de-escalation [4,8]. Furthermore, why HPV-positive HNSCCs have a better prognosis compared to HPV-negative is a question of interest. Finally, there is an impetus to identify novel therapeutic targets that can enhance responses to radiotherapy or immunotherapy or can function independently. Cancer/testis antigens represent a compelling class of molecules that may fill a niche in each of these research needs.

\section{Cancer-Testis Antigens}

\section{Overview}

Cancer-testis (CT) antigens encompass a set of proteins whose expression is predominantly limited to germ cells or trophoblasts but is aberrantly activated in cancers [9,10]. Because of their immunogenicity and limited expression, $\mathrm{CT}$ antigens have sparked interest as attractive targets for tumor-specific immunotherapies. The first CT antigen, melanoma antigen (MAGE)-1 - now known as MAGEA1- was discovered in 1991 using autologous typing, a technique in which tumor cells from a patient are co-cultured with autologous lymphocytes to test for the generation of $\mathrm{T}$ cells that target tumor antigens [10-12]. Autologous cytotoxic T lymphocytes targeting melanoma cells from a patient with a favorable clinical course were generated and the gene encoding one of the targeted tumor antigens was cloned and named MAGE1 [10,11]. MAGE2 and MAGE3 were also identified in the study, revealing MAGE to be a gene family [11]. Other CT antigens including B melanoma antigen (BAGE) [13] and G antigen 1 (GAGE1) [14] were subsequently discovered using cytotoxic $\mathrm{T}$ lymphocytes from the same patient [10]. Serological analysis of cDNA expression libraries (SEREX), in which cDNA expression libraries are screened using patient antibodies, was the subsequent dominant approach and led to the discovery of SSX [15], synaptonemal complex protein 1 (SYCP1) [16], and the New York esophageal squamous cell carcinoma 1 (NY-ESO-1) [17], among others [10]. Approaches to identify novel CT antigens have expanded to in silico identification based on mRNA expression patterns [18-20]. While this shift has augmented the CT antigen cohort, a caveat is that the coding products of some of these CT genes have not been formally tested for their immunogenicity [18]. The Cancer-Testis database (CTdatabase), a list of CT genes compiled based on the literature and computational prediction, currently contains 276 genes [12]. A larger list of 1019 CT genes has been compiled through transcriptomic analysis integrating data from multiple publicly available datasets across normal tissues and 19 cancer types [20]. The abundance of available expression data has revealed the expression of genes previously characterized as CT-restricted in other normal tissues. Thus, the description of CT antigens has evolved from "testis-restricted" to the less stringent "testis-preferred", with further sub-classification into "testis-restricted", "testis-brain restricted", and "testis-selective" groups [19].

A separate classification for CT genes can be made based on chromosomal location: CT- $\mathrm{X}$ genes encoded on the $\mathrm{X}$ chromosome and non-X CT genes encoded autosomally [10]. CT-X genes comprise 
several multi-gene families, including MAGE, GAGE, PAGE, SSX, CTAG, and SPANX [9,21]. CT-X genes are largely expressed in spermatogonia while non-X CT genes seem to be preferentially expressed in later stages of germ cell differentiation [10].

Epigenetic deregulation, particularly DNA demethylation, plays a prominent role in the aberrant expression of CT genes in cancers [22]. For example, demethylation of CpG sites in the MAGE-A1 promoter is correlated with its expression in cancers [23,24]. Treatment with the demethylating agent 5 -aza-2-deoxycytidine promotes the expression of a spectrum of CT genes in different cellular backgrounds [23-25]. DNA methyltransferases DNMT1 and DNMT3b appear to play a role in silencing, as loss of both but not either alone lead to de-repression of the CT genes TPTE, BRDT, and SYCP1 in colon cancer cell lines [25]. Acetylation may also play a role in expression. It was shown that while treatment of cancer cell lines with histone deacetylase (HDAC) inhibitor trichostatin A led to minimal effects on MAGE-A gene expression, treatment with both trichostatin A and DNA methylase inhibitor 5-aza-CdR led to synergistic expression increases over 5-aza-CdR alone [26]. CT gene expression can also be modulated by transcription factors or regulators such as Sp1, p53, or the Brother of the Regulator of Imprinted Sites (BORIS), a paralog of the 11-zinc-finger gene regulator CTCF $[22,27-30]$. Such findings may be leveraged therapeutically to amplify CT antigen expression and enhance the efficacy of immunotherapies.

\section{CT antigens in immunotherapy}

$\mathrm{CT}$ antigens have served as targets for the development of cancer vaccines and engineered T-cellbased therapeutics. Therapeutic approaches including peptide-based CT antigen vaccines, engineered $\mathrm{T}$ cells, checkpoint inhibitors in complement with peptide vaccines, and lentiviral vectorbased vaccines have been the foundation of multiple clinical trials and have shown some clinical promise [31-36]. Examples of specific trials in HNSCC will be discussed in a later section.

\section{Hallmarks of cancer co-opted by CT antigens}

Despite profound interest in the promise of $\mathrm{CT}$ antigens as immunotherapy targets, a fundamental question in the field is whether CT antigens play a mechanistic role as drivers of carcinogenesis or whether their expression reflects merely a consequence of oncogenic epigenetic reprogramming. A burgeoning body of evidence suggests active roles for many of these proteins in oncogenic progression. Hanahan and Weinberg defined the "Hallmarks of Cancer", a framework for understanding acquired cellular capabilities that enable carcinogenic initiation and progression [37]. While the oncogenic mechanisms of CT antigens have been reviewed elsewhere [10,18,22,38], the following provides examples of how $\mathrm{CT}$ antigens are involved in regulating hallmarks of cancer.

\section{Sustaining proliferative signaling, resisting cell death, evading growth suppressors}

In a multidimensional siRNA-based functional screen, $140 \mathrm{CT}$ antigens were independently depleted in 11 cancer cell lines. This was followed by an assessment of viability, apoptosis, and proliferation. Through this screen and subsequent validation, NY-ESO-1, FTHL17, and SPATA19 were identified as required for tumor cell proliferation and COX6B2 and CALR3 as essential for survival. Other factors validated to affect apoptosis, viability, or proliferation included MAGEA8, MAGEA2, SSX1, CTAG1B, IGSF11, CSAG1, CSAG3, CCDC110, ZNF165, and FATE1 [39]. 
Elsewhere in the literature, numerous CT antigens, including but not limited to CT45A1, PIWIL2, COX6B2, SPANX, DDX43, MAGE family members, CAGE, and SPAG6 have been implicated in cell viability, proliferation, clonogenic growth, and/or and anchorage-independent colony growth [4050]. CT antigens have been shown to inhibit apoptosis and promote resistance to chemotherapeutics. Multiple CT antigens share mechanisms that converge on the p53 tumor suppressor, a transcription factor that engages cytostatic or cytotoxic responses to various cellular insults and is the most frequently mutated gene in human cancers [51]. For example, MAGEA2, which promotes cancer cell resistance to etoposide treatment, interacts with the DNA binding domain of p53, thereby inhibiting p53-mediated activation of target gene expression [52,53]. It also impairs its acetylation, a stabilizing post-translational modification that enhances p53's transcriptional activity [53,54]. CSAG2 inhibits p53 by promoting its deacetylation by SIRT1, which may mediate resistance to genotoxic stressors such as doxorubicin or $\mathrm{H}_{2} \mathrm{O}_{2}$ [44]. CAGE, whose overexpression confers resistance to chemotherapeutic agents such as taxol, also negatively regulates p53 expression [55].

\section{Activating invasion and metastasis and Inducing angiogenesis}

CT45A1 overexpression in osteosarcoma cells significantly increased the number of lung metastases in an in vivo metastasis assay [40]. Cell invasion and migration, two key cellular capabilities integral to the metastatic cascade [56], were also enhanced when CT45A1 was ectopically expressed in cells [40]. OIP5 is required for efficient in vitro invasion and migration of glioblastoma cells [50]. CAGE has been shown to promote both the metastatic and angiogenic potential of cancer cells [57].

\section{Deregulating cellular energetics}

In cancers, energy metabolism is reprogrammed towards an increased reliance on glycolysis even in the presence of sufficient oxygen. This switch to aerobic glycolysis is hypothesized to funnel glycolytic intermediates into various biosynthetic pathways that support the cells' proliferative drive, such as generating nucleosides and amino acids [37]. The CT antigens semenogelin 1 and 2 (SEMG1 and SEMG2) interact with and increase the levels and activity of metabolic enzymes: both affect pyruvate kinase M2 (PKM2), and SEMG1 also affects lactate dehydrogenase A (LDHA) [58]. PKM2 catalyzes the last step in glycolysis [59] while LDHA catalyzes the conversion of pyruvate to lactate and contributes to aerobic glycolysis [60], and both have been implicated as pro-tumorigenic proteins $[59,60]$. Overexpressing SEMG1 and SEMG2 also increases mitochondrial membrane potential (MMP) as well as both glycolysis and oxygen consumption rate [58]. Sperm are energetically demanding cells, requiring increased ATP for motility, and thus possess tissue-specific protein isoforms for both glycolysis and oxidative phosphorylation (OXPHOS) that allow them to meet these enhanced demands. COX6B2, a testis-specific subunit of cytochrome c oxidase (complex IV), enhances mitochondrial OXPHOS in tumor cells, which in turn promotes proliferation. COX6B2 is also induced by hypoxia and promotes cell proliferation in the face of hypoxic conditions [43]. MAGEA6 expression increases cellular growth compared to control cells following glycolytic inhibition with 2-deoxy-D-glucose (2-DG) [61]. 2-DG-treated MAGEA6-expressing cells enhance the synthesis of fatty acids. Concomitant treatment with etomoxir, a fatty acid oxidation inhibitor [62], attenuates the MAGEA6-induced growth advantage under conditions of 2-DG challenge, suggesting that MAGEA6 drives cell growth through fuel switching to fatty acid oxidation [61]. 
5 of 29

Genome instability and mutation

In triple-negative breast cancers (TNBCs), HORMAD1 expression can increase structural chromosomal abnormalities and chromosomal instability, in particular allelic-imbalanced copy number aberrations (AiCNA). HORMAD1 represses homologous recombination (HR) and inhibits the repair of spontaneously generated double-stranded DNA breaks. Nonhomologous end joining (NHEJ), a DSB repair process often upregulated in the context of HR deficiency, is upregulated by HORMAD1 overexpression, which can facilitate AiCNA formation. HR-deficient cancer cells can exhibit enhanced sensitivity to platinum-based chemotherapeutics and poly (ADP-ribose)polymerase (PARP) inhibitors. Accordingly, HORMAD1-overexpressing TNBCs exhibit enhanced sensitivity to cisplatin and PARP inhibitors [63].

Furthermore, HORMAD1 overexpression abrogates DNA mismatch repair in ovarian and alveolar adenocarcinoma as well breast ductal carcinoma cell lines. This perturbation depends on interactions between HORMAD1 and the MCM8-MCM9 complex. High HORMAD1 overexpression is associated with increased tumor burden and neoantigen counts in breast invasive carcinoma, head and neck squamous cell carcinoma, lung adenocarcinoma, and thymoma in an analysis of genomes deposited in The Cancer Genome Atlas (TCGA). TCGA analysis also revealed associations between HORMAD1 expression and genomic instability features including copy number alteration and loss of heterozygosity [64].

In summary, CT antigens have been reported to promote almost all hallmarks of cancer and regulate known oncogenic and tumor-suppressive signaling modules. This growing body of evidence suggests that the expression of CT antigens is more than an artifact and may drive carcinogenic processes.

\section{HNSCC and CT antigens}

The expression of CT genes in HNSCC has been noted in the literature for over 20 years - some of the earliest reports include the detection of MAGEA3 [65], GAGE-1, and GAGE-2 [66], and LAGE-1 [67] expression in tumor tissues. Since then, studies have noted the expression of other CT antigens in HNSCC and analyzed correlations between expression and prognosis. These findings, which underscore the relevance and potential of CT antigens to serve as therapeutic targets and clinical course biomarkers in HNSCC, are summarized in Table 1.

Table 1: Expression and clinical correlates of CT antigens in HNSCC

\begin{tabular}{|l|l|l|l|}
\hline $\begin{array}{l}\text { Expressed } \\
\text { CT }\end{array}$ & & $\begin{array}{l}\text { References reporting } \\
\text { gene/antigen }\end{array}$ & $\begin{array}{l}\text { Prognostic associations in } \\
\text { expression in HNSCC } \\
\text { tumors }\end{array}$ \\
\hline & Oncogenic functions & $\begin{array}{l}\text { Associated with tumor regional } \\
\text { recurrence, worse overall survival } \\
\text { among HPV-negative patients } \\
\text { and all patients not stratified by }\end{array}$ & \\
\hline MAGEA1 & $\begin{array}{l}\text { Proliferation, invasion, migration } \\
\text { HPV status }[8,68]\end{array}$ & {$[8,68-74]$} \\
\hline
\end{tabular}


6 of 29

\begin{tabular}{|c|c|c|c|}
\hline MAGEA2 & $\begin{array}{l}\text { Proliferation, suppress cell cycle } \\
\text { arrest through p53 [75] }\end{array}$ & & [71] \\
\hline MAGEA3 & $\begin{array}{l}\text { Proliferation, migration, invasion } \\
\text { [76-78] }\end{array}$ & $\begin{array}{l}\text { Associated with tumor regional } \\
\text { recurrence, worse overall survival } \\
{[8,68]}\end{array}$ & {$[8,65,68,71,72,79]$} \\
\hline MAGEA3/6 & $\begin{array}{l}\text { Proliferation, migration, invasion, } \\
\text { anchorage-independent growth } \\
{[80-82]}\end{array}$ & $\begin{array}{l}\text { Associated with improved } \\
\text { disease-free survival [73] }\end{array}$ & [73] \\
\hline MAGEA4 & $\begin{array}{l}\text { Activate trans-lesion synthesis } \\
\text { (genomic instability), inhibit } \\
\text { apoptosis, inhibit growth arrest } \\
{[83,84]}\end{array}$ & $\begin{array}{l}\text { Associated with worse overall } \\
\text { survival among HPV-negative } \\
\text { patients and all patients not } \\
\text { stratified by HPV status [8] }\end{array}$ & {$[8,68,71,73,74,84-88]$} \\
\hline MAGEA6 & Inhibit cell death [89] & & [71] \\
\hline MAGEA9 & $\begin{array}{l}\text { Proliferation, migration, } \\
\text { chemoresistance [90] }\end{array}$ & $\begin{array}{l}\text { Associated with worse overall } \\
\text { survival [8] }\end{array}$ & {$[8,73]$} \\
\hline MAGEA10 & & & [74] \\
\hline MAGEA11 & $\begin{array}{l}\text { Resistance to epidermal growth } \\
\text { factor receptor inhibitors [91] }\end{array}$ & $\begin{array}{l}\text { Associated with worse 5-year } \\
\text { overall survival rate [92] }\end{array}$ & [91-93] \\
\hline MAGEA12 & Migration, invasion [94] & & {$[73,74]$} \\
\hline MAGEB2 & Proliferation $[80,95,96]$ & & [73] \\
\hline MAGEB6 & & & [73] \\
\hline MAGEC1 & Inhibit apoptosis [49] & & {$[68,70,73,79,85,97]$} \\
\hline MAGEC2 & $\begin{array}{l}\text { Proliferation, amoeboid migration, } \\
\text { metastasis }[80,98,99]\end{array}$ & & {$[68,70,73,79,97,100]$} \\
\hline NY-ESO-1 & & $\begin{array}{l}\text { Associated with worse overall } \\
\text { survival [70] }\end{array}$ & {$[68,70,72,74,79,87,97,100,101]$} \\
\hline SSX & $\begin{array}{l}\text { In vivo tumor growth, invasion, } \\
\text { migration }[102,103]\end{array}$ & $\begin{array}{l}\text { Associated with worse overall } \\
\text { survival [8] }\end{array}$ & {$[8,79,100]$} \\
\hline IMP1 & $\begin{array}{l}\text { Invasion, promotion of stemness } \\
\text { [104] }\end{array}$ & $\begin{array}{l}\text { Associated with worse overall } \\
\text { survival among HPV-positive } \\
\text { patients and among all patients } \\
\text { not stratified by HPV status [8] }\end{array}$ & [8] \\
\hline SAGE & & & {$[79,87,97]$} \\
\hline BAGE & & & [79] \\
\hline GAGE & $\begin{array}{l}\text { Anti-apoptotic activity, } \\
\text { radioresistance, chemoresistance } \\
{[105]}\end{array}$ & $\begin{array}{l}\text { Associated with lymph node } \\
\text { metastases [93] }\end{array}$ & {$[14,74,79,93,100,106]$} \\
\hline CRISP2 & & & {$[73]$} \\
\hline
\end{tabular}




\begin{tabular}{|c|c|c|c|}
\hline PRAME & $\begin{array}{l}\text { Binds to retinoic acid receptor } \\
\text { (RAR) and inhibits its } \\
\text { transcriptional activation. Inhibits } \\
\text { differentiation, apoptosis, arrest of } \\
\text { proliferation typically induced by } \\
\text { retinoic acid. }[107,108]\end{array}$ & & {$[73,74,109]$} \\
\hline NY-TLU-57 & & & [79] \\
\hline SPANX & Proliferation [45] & & [73] \\
\hline CXORF48 & & & [73] \\
\hline $\begin{array}{l}\text { HOM-TES- } \\
85\end{array}$ & & & [79] \\
\hline SYCP1 & & & {$[79]$} \\
\hline \multirow[t]{2}{*}{ CT45 } & Stemness, chemoresistance [110] & & [97] \\
\hline & Chemosensitivity [111] & & \\
\hline NXF2 & & & [97] \\
\hline XAGE1 & & $\begin{array}{l}\text { Associated with lymph node } \\
\text { metastases [93] }\end{array}$ & {$[93]$} \\
\hline CTAGE & & & {$[112]$} \\
\hline SP17 & $\begin{array}{l}\text { In vivo tumor growth, } \\
\text { chemoresistance, migration } \\
{[113,114]}\end{array}$ & & [115] \\
\hline BRDT & $\begin{array}{l}\text { Proliferation, migration, inhibition } \\
\text { of apoptosis }[116,117]\end{array}$ & & [118] \\
\hline ACTL8 & $\begin{array}{l}\text { Proliferation, invasion, migration } \\
{[119,120]}\end{array}$ & $\begin{array}{l}\text { Associated with worse prognosis } \\
{[120]}\end{array}$ & {$[120]$} \\
\hline PLAC1 & $\begin{array}{l}\text { Proliferation, migration, invasion } \\
{[121,122]}\end{array}$ & & [123] \\
\hline
\end{tabular}

Multiple clinical trials leveraging CT antigens in the context of HNSCC have been completed or are ongoing. A phase II randomized controlled clinical trial was completed examining the safety and efficacy of MAGEA3 vaccine GL-0817 in combination with adjuvants for the prevention of oral squamous cell carcinoma recurrence in high-risk patients (NCT02873819) $[124,125]$. A phase I trial was completed examining the safety, kinetics, and clinical effect of $\mathrm{T}$ lymphocytes transduced with a MAGEA4-specific T-cell receptor gene in patients with unresectable, treatment-refractory solid tumors, including HNSCC (NCT02096614) [126]. Phase I trials have been completed investigating engineered T-cell receptor T lymphocyte therapy targeting NY-ESO-1 in patients with treatmentrefractory solid tumors including HNSCC ( $\underline{\mathrm{NCT} 03159585}$, NCT02366546) $[124,127,128]$. The results for these trials have not yet been released. A nonrandomized phase II clinical trial was conducted in which advanced stage HNSCC patients resistant to standard therapy were vaccinated with peptides derived from CT antigens Ly6K, CDCA1, and IMP3. Vaccinated patients exhibited significantly 
longer overall survival times than those receiving the best supportive care. Not all patients in the vaccination arm exhibited a cytotoxic T-lymphocyte (CTL) response, although those with a CTL response to LY6K or CDCA1 exhibited significantly longer overall survival compared to nonresponders: 8.1 vs. 1.4 months and 11.3 vs. 4.6 months, respectively. After dividing vaccinated patients into groups based on the number of antigens to which they mounted a CTL response, the overall survival was longer for those who responded to more antigens, with a 19.5-month mean survival time in patients with CTL responses to all three antigens [129]. CT antigens thus hold potential as immunotherapeutic targets in HNSCC.

\section{Contribution of CT antigens to HPV-associated HNSCCs} HPV Molecular Biology and Mechanisms of Carcinogenesis

HPVs are non-enveloped double-stranded DNA viruses with an approximately 8000 base-pair genome. They are divided into five genera: alpha, beta gamma, mu, and nu. The alpha genus HPVs, which primarily infect mucosal epithelia, are further subdivided into the high-risk and low-risk types. Nearly all cases of cervical cancer and a large proportion of oropharyngeal and other anogenital cancers are caused by high-risk alpha HPVs. The low-risk alpha HPVs are not etiological agents in cancer - rather, they are associated with benign wart pathologies. The beta and gamma genus HPVs primarily infect cutaneous epithelia. Beta genus HPVs are the etiological agents in cutaneous squamous cell carcinoma ( $\mathrm{CSCC}$ ) in patients with the rare genetic disorder Epidermodysplasia Verruciformis and may contribute to cSCCs in immunocompromised patients. E6 and E7 are the primary viral oncoproteins [130]. A vast body of literature has accumulated on the biological activities and oncogenic mechanisms of these proteins, which are reviewed elsewhere [130-133].

HPV-positive HNSCCs represent a distinct clinical entity that has a favorable prognosis compared to HPV-negative HNSCCs [134]. The enhanced survival rate is thought to be due to higher chemotherapy and radiotherapy sensitivity, although the underlying mechanisms are not completely understood [135]. The following section will explore the relevance of CT antigens to HPV-associated HNSCC.

\section{CT antigen expression in HPV-positive HNSCCs}

The literature is sparse regarding the role of CT antigens in HPV-positive cancers. Evidence from some studies suggests that $\mathrm{CT}$ antigens are present and recognized by the immune system in HPVpositive HNSCC patients and may serve as prognostic biomarkers. One study examining antibody responses to $16 \mathrm{CT}$ antigens in HNSCC patients identified a subset of HPV-positive patients who exhibited responses, although there was considerable heterogeneity in the target signatures [136]. A related study examined prognostic trends in HNSCC patient antibody responses to $16 \mathrm{CT}$ antigens, stratified by HPV status. Among HPV-positive patients, antibody response to IMP-1 was associated with significantly shorter overall survival: mean 109.3 months for IMP-1 response positive patients compared to 41.2 months for negative response patients. Indeed, HPV-positive patients with an IMP1 antibody response had a prognosis that was not significantly different compared to HPV-negative patients [8]. Although HPV-positive HNSCC patients typically exhibit an improved prognosis compared to HPV-negative patients [134], there is still a subset of patients who are considered poor 
responders [137]. These results suggest that HPV-positive HNSCC patients could be stratified by CT antigen signature to predict prognosis and, potentially, response to therapy. Given the considerable morbidity associated with current HNSCC treatments, there is great interest in chemotherapy and radiotherapy dose de-escalation, although recent clinical trials have shown detrimental outcomes with de-escalation [138]. CT antigen signatures - whether gene expression or antibody response may serve as biomarkers to identify subsets of HPV-positive patients for which radiotherapy dose de-escalation may be safely pursued. The reported studies examined only $16 \mathrm{CT}$ antigens, a fraction of the documented repertoire. Additional studies where a broader range of $\mathrm{CT}$ antigens is assessed are warranted to identify signatures that can serve as biomarkers for good prognosis and potential dose de-escalation.

Multiple studies comparing gene expression differences between HPV-positive versus HPV-negative HNSCC have found multiple CT genes to be differentially regulated. CT genes that are significantly upregulated in HPV-positive versus negative HNSCCs are listed in Table 2. The following section elaborates on the physiological functions and potential oncogenic mechanisms of select upregulated CT genes identified in at least two independent studies.

Table 2 - CT genes significantly upregulated in HPV-positive HNSCC compared to HPV-negative HNSCC. Wang et. al., 2016 [20] was used to define the CT gene reference list

\begin{tabular}{|l|l|}
\hline CT Gene & Reference \\
\hline SYCP2 & {$[137][139][140][141][142][143]$} \\
\hline STAG3 & {$[137][140][144]$} \\
\hline TAF7L & {$[137][139][140]$} \\
\hline YBX2 & {$[137][139][144]$} \\
\hline RIBC2 & {$[137][144]$} \\
\hline ZCWPW1 & {$[137][144]$} \\
\hline POU4F1 & {$[137][145]$} \\
\hline DDX43 & {$[145]$} \\
\hline LDHC & {$[137]$} \\
\hline TCP11 & {$[137]$} \\
\hline FKBP6 & {$[137]$} \\
\hline SOX30 & {$[137]$} \\
\hline SMC1B & {$[137]$} \\
\hline DDX25 & {$[137]$} \\
\hline YPEL1 & {$[137]$} \\
\hline KIF15 & {$[137]$} \\
\hline CENPH & {$[137]$} \\
\hline C19orf57 & {$[137]$} \\
\hline BCL2L14 & {$[137]$} \\
\hline
\end{tabular}




\begin{tabular}{|l|l|}
\hline SHCBP1L & {$[137]$} \\
\hline ZNF541 & {$[137]$} \\
\hline IZUMO4 & {$[137]$} \\
\hline ZPBP2 & {$[137]$} \\
\hline CNTD1 & {$[137]$} \\
\hline RAD9B & {$[137]$} \\
\hline CCDC155 & {$[137]$} \\
\hline SYCE2 & {$[137]$} \\
\hline PRR19 & {$[137]$} \\
\hline KIF24 & {$[137]$} \\
\hline
\end{tabular}

\section{SYCP2}

As mentioned previously, the Synaptonemal complex protein 2 (SYCP2) protein is a component of the synaptonemal complex, which joins homologous chromosomes prior to meiotic recombination [146]. The synaptonemal complex consists of two axial/lateral elements, a central element, and transverse filaments [147]. During the first stage of meiotic prophase I, called leptotene, chromosomes condense, and the sister chromatids organize along the axial elements. Meiotic DNA double-stranded breaks (DSBs) are formed and sequence matching on the homologous chromosome aligns the axial elements. During the next stage, zygotene, transverse filaments connect the axial elements, continuing until the length of the chromosome is joined by the synaptonemal complex. This state is called synapsis and is achieved by the beginning of the pachytene stage. The axial elements are incorporated into the synaptonemal complex as lateral elements. The pachytene stage includes the formation and resolution of the double Holliday Junction into crossovers. During diplotene, the synaptonemal complex disassembles and homologous chromosomes separate except at chiasmata $[148,149]$. SYCP2 is required for the formation of axial elements as well as synapsis during male meiosis [149-151]. In mice, Sycp2 knockout leads to reduced female fertility, male sterility and meiotic arrest, and spermatocyte apoptosis [149]. In zebrafish spermatocytes, in addition to its role in synaptonemal complex assembly, SYCP2 is also important for homologous pairing and meiotic double-stranded break formation [152]. While few studies have focused on the role of SYCP2 in cancer, others provide further evidence that SYCP2 expression is characteristic of HPV-associated cancers. SYCP2 was found to be one of the six most differentially expressed genes in HPV-positive cervical cancer compared to cervical epithelium control tissues and exhibits increasing expression levels in the progression from normal tissue to pre-cancerous lesions to cervical cancer [153,154]. SYCP2 expression was detected in HPV16 positive but not negative keratinocyte lines and expression was promoted synergistically by HPV16 E6 and E7 [140]. As mentioned previously, synaptonemal complex components SYCP1, SYCP2, SYCP3, SYCE1, and SYCE2 are expressed in cancers [147]. Expression of synaptonemal complex axial/lateral element SYCP3 [147] in somatic cells impairs the RAD51-mediated homologous recombination pathway, enhances sensitivity to DNA damaging agents or poly(ADP-ribose) polymerase (PARP) inhibition, and promotes chromosomal instability. SYCP3 interacts with BRCA2 and can inhibit its function in homologous recombination [155]. Given 
that HPV16 E6 and E7 can induce DNA damage [156] and promote genomic instability [157], it is conceivable to hypothesize that SYCP2 upregulation promotes this hallmark of cancer.

\section{ZCWPW1}

Zinc finger CW-type and PWWP domain containing 1 (ZCWPW1) is a reader of Histone H3 trimethylation marks on lysine 4 and/or lysine 36 (H3K4me3 and H3K36me, respectively) [158] [159]. In meiosis, H3K4me3 and H3K36me3 mark meiotic DSBs and are written by the methyltransferase PR domain zinc finger protein 9 (PRDM9) [158,160-162]. ZCWPW1 binds to these dual PRDM9-dependent histone methylation marks at meiotic recombination DSB hotspots [158,159,163]. Zcwpw1 loss in male mice leads to azoospermia [158] and impairs meiotic prophase I processes including synapsis, meiotic recombination, and meiotic DSB repair $[158,163,164]$. The precise mechanism for how ZCWPW1 might facilitate DSB repair is unknown, although one hypothesis is that it nucleates repair machinery [159]. Although ZCWPW1 binds with higher affinity to dual H3K4me3/H3K36me3 peptides, it can bind to each mark individually [158]. Independently of PRDM9, ZCWPW1 can also bind to CpG dinucleotides and interact with Alu repeats in a CpGdependent manner - it has a greater affinity for methylated CpGs, although can also to bind nonmethylated regions [163]. While there are no studies that have investigated a potential mechanistic link between ZCWPW1 and cancer, H3K4 and H3K36 readers play a role in diverse cancers [165,166], as do methyl-CpG binding proteins [167].

\section{TAF7L}

TATA-binding protein-associated factor 7L (TAF7L) is an X-linked paralog of the transcription factor IID (TFIID) subunit TAF7 that is predominantly restricted to germ cells in the testis [168]. TFIID is a critical factor for the initiation of RNA polymerase II-mediated gene transcription. It consists of the TATA-binding protein (TBP), which binds to the TATA element present in many promoters, in addition to 13-14 TBP-associated factors (TAFs). TAF7L is expressed at multiple stages in the germ cell differentiation process, including in spermatogonia, spermatocytes, and haploid round spermatids, and acts as a TFIID subunit with opposing expression patterns to paralog TAF7. TAF7L interacts with TBP and TFIID subunit TAF1 [168]. Loss of Taf $7 l$ in male mice (Taf $7 l^{-1 Y}$ ) leads to smaller litters, sperm tail structural defects, and decreased sperm motility [169], although continued backcrossing of Taf $7 l^{-1 Y}$ mice can lead to sterility [170]. Taf $7 l^{-1 Y}$ testes exhibit pronounced gene expression remodeling, with notable downregulation of genes involved in spermatogenesis, sperm motility, and metabolism [169,170]. Of note, expression of Sex comb-like with four MBT domains 2 (SFMBT2), a Polycomb group (PcG) protein that may have an oncogenic role [171], was downregulated with Taf $7 l$ ablation [169]. While TAF7L was initially thought to be testis-specific, studies later revealed its expression in adipocytes and suggested a role in adipocyte differentiation [172]. TAF7L can also function as a molecular switch specifying brown fat or muscle cell fate, with TAF7L expression favoring brown adipose tissue formation [173]. Aberrant TAF7L expression might lead to transcriptional reprogramming that can promote cancer progression.

\section{STAG3}

Stromal antigen 3 (STAG3) is a germline and meiosis I-specific subunit of cohesin [174]. Cohesin is a ring-shaped four-subunit complex that mediates sister chromatid cohesion, a function that is vital for 
chromosome segregation and DNA repair [175]. Cohesins comprise two structural maintenance of chromosomes (SMC) proteins, the kleisin subunit, and a stromal antigen (STAG) [175]. In somatic cells, the SMC proteins are SMC1 and SMC3; the kleisin subunit is RAD21; and the stromal antigen is STAG1 or STAG2 [175]. In the germline, the meiosis-specific cohesin proteins are the SMC protein SMC1 $\beta$, kleisin REC8 or RAD21L, and the stromal antigen STAG3 [175,176]. STAG3 loss is associated with sterility, disrupted synaptonemal complex assembly and synapsis, impaired centromeric and telomeric sister chromatid cohesion, and dysfunctional meiotic recombination [177-180]. Loss of STAG3 also leads to impaired repair of programmed double-stranded breaks (DSBs) and defective DNA damage response $[179,180]$. Ataxia-telangiectasia and RAD3-related (ATR), a serine/threonine kinase, is typically activated by single-stranded DNA (ssDNA) and triggers downstream responses including cell cycle arrest, DNA repair, fork stabilization, and apoptosis in somatic cells [181]. In meiosis, during zygotene, ATR and ATR interacting protein (ATRIP) activate the DNA damage response to signal the presence of recombination intermediates. ATR typically localizes to unsynapsed chromosome regions during zygonema and dissociates following synapsis. Stag3 mutant mice exhibit aberrant ATR and ATRIP localization [180]. In a separate report, STAG3 was shown to interact with PRDM9, which marks recombination hotspots via its histone methyltransferase activity, and promote meiotic programmed DSBs at both PRDM9-dependent and independent hotspots [182]. Mechanistically, STAG3 facilitates localization of DSB-promoting proteins HORMAD1, IHO1, and MEI4 to the chromosome axis and mediates double-stranded break forming activities of SPO11 [182].

STAG3 expression is silenced in somatic cells by E2F6, a transcriptional repressor that is a component of Polycomb repressive complexes (PRC) [183]. MAX Gene-Associated (MGA), a component of the non-canonical PRC1.6, also mediates the repression of STAG3 and other meiotic genes [184]. Given that HPV16 E7 interacts with E2F6, inhibits its transcription repressive functions, and attenuates the Polycomb group (PcG)-mediated formation of heterochromatin-associated nuclear foci [185], one may hypothesize that HPV promotes aberrant STAG3 expression through abrogation of E2F6 repression.

Although the physiological role of STAG3 is actively being characterized, there are fewer studies on its role in carcinogenesis. Given its meiotic activities, one might hypothesize STAG3 to interplay with the DNA damage response and play a role in promoting genomic instability. Loss of STAG3 in melanoma leads to BRAF inhibitor resistance [186]. However, STAG3 overexpression is also a common event in various cancers [187]. In HNSCCs not stratified by HPV status, STAG3 expression is associated with improved overall survival and progression-free interval [144]. Conversely, high STAG3 expression is associated with poor prognosis, metastasis, and disease recurrence in colorectal cancer patients [188]. In colorectal cancer cell lines, STAG3 downregulation enhances sensitivity to chemotherapeutics and impairs DNA damage repair [188]. Cohesin complex components are frequently mutated in cancers and mitotic stromal antigen 2 (STAG2) is the second most commonly mutated gene in Ewing sarcoma $[189,190]$. In line with their role in chromosome segregation, somatic mutations in cohesin subunit genes have been reported to promote chromosomal instability in cancers - an "enabling hallmark" of cancer that is characterized by higher rates of chromosome missegregation during mitosis, leading to aneuploidy as well as translocations, and loss of 
heterozygosity, among other defects [189,191-193]. However, cohesin subunit mutations have also been reported in chromosomally stable tumors without correlation between mutation and aneuploidy, suggesting that cohesin subunit mutations may drive oncogenesis through alternative mechanisms unrelated to chromosomal instability $[189,194,195]$. While these studies suggest a tumorsuppressive role for cohesin subunits, aberrant cohesin overexpression is also observed in cancers and there is evidence that this may activate oncogenic transcription [196]. Further investigations are warranted to understand how STAG3 affects genomic instability and carcinogenesis in HPVassociated cancers.

\section{Conclusions}

Since their discovery, CT antigens have ignited interest as promising targets for cancer immunotherapies. Many of them are expressed in HNSCC and the possibility of clinical translation using engineered T cells and cancer vaccines is already being investigated in clinical trials. Although the viral antigens within HPV-positive cancers are immunogenic and numerous clinical trials testing immunotherapies targeting HPV16 E6/E7 are underway, the response rates have been disappointing and leave room for improvement. For example, the ISA 101 trial that tested peptide vaccines targeting HPV16 E6/E7 demonstrated a 33\% response rate [124]. Targeting both upregulated CT antigens and viral antigens may be one strategy to improve responses. HPV-positive HNSCCs are a distinct clinical entity with an improved prognosis compared to HPV-negative cancers [134]. Despite the improved prognosis, the current non-surgical standard-of-care treatment - high-dose cisplatin concurrent with radiotherapy - is associated with significant morbidity. As such, there is an impetus to de-escalate treatment via reducing radiation dose and/or type and dose of chemotherapy. Three recent deescalation clinical trials found worse clinical outcomes when reducing the cisplatin dose [138]. Given that antibody response to CT antigens such as IMP-1 can stratify HPV-positive HNSCC based on prognosis, it may be possible to use CT antigen signatures as biomarkers for chemoradiotherapy response to identifying those most likely to benefit from de-escalation. The mechanism of the enhanced therapeutic sensitivity and improved prognosis associated with HPV-positive HNSCC is not fully understood [135]. Given that some CT antigens upregulated in HPV-positive cancers may affect DNA break repair and the DNA damage response, it is conceivable that aberrant CT antigen expression may contribute to chemo- and radiosensitivity. Although there is evidence that CT antigens can promote nearly all hallmarks of cancer [37], for many individual CT genes, whether and how their somatic expression contributes to oncogenesis remains unknown. In addition to shaping immunotherapy and treatment-guiding biomarker development, further study on CT antigens provides a unique opportunity to uncover novel oncogenic mechanisms, reveal new drug targets or targetable collateral sensitivities, and provide molecular insights into the distinct clinical characteristics of HPV-positive HNSCC.

Author Contributions: S.C.W. - writing the original draft. K.M. - editing, revising, supervision, funding Funding: This work is funded by National Institutes of Health (NIH) grants CA228543, AI147176, AI166786 (K.M.); GM008448 Medical Scientist Training Grant at Tufts University; and Tufts Collaborative Cancer Biology Award from the Tufts Graduate School of Biomedical Sciences (S.W.) 
Acknowledgments: We acknowledge members of the Münger lab for helpful discussions and the NIH for funding to K.M.

Conflicts of Interest: The authors declare no conflicts of interest

\section{References}

1. Johnson, D.E.; Burtness, B.; Leemans, C.R.; Lui, V.W.Y.; Bauman, J.E.; Grandis, J.R. Head and neck squamous cell carcinoma. Nat. Rev. Dis. Prim. 2020, 6, 92, doi:10.1038/s41572-020-002243.

2. Sung, H.; Ferlay, J.; Siegel, R.L.; Laversanne, M.; Soerjomataram, I.; Jemal, A.; Bray, F. Global Cancer Statistics 2020: GLOBOCAN Estimates of Incidence and Mortality Worldwide for 36 Cancers in 185 Countries. CA. Cancer J. Clin. 2021, 71, 209-249, doi:10.3322/caac.21660.

3. Braakhuis, B.J.M.; Brakenhoff, R.H.; René leemans, C. Treatment choice for locally advanced head and neck cancers on the basis of risk factors: Biological risk factors. Ann. Oncol. 2012, 23, x173-x177, doi:10.1093/annonc/mds299.

4. Chow, L.Q.M. Head and Neck Cancer. N. Engl. J. Med. 2020, 382, 60-72, doi:10.1056/NEJMRA1715715.

5. Morris, L.G.T.; Chandramohan, R.; West, L.; Zehir, A.; Chakravarty, D.; Pfister, D.G.; Wong, R.J.; Lee, N.Y.; Sherman, E.J.; Baxi, S.S.; et al. The molecular landscape of recurrent and metastatic head and neck cancers insights from a precision oncology sequencing platform. JAMA Oncol. 2017, 3, 244-255, doi:10.1001/jamaoncol.2016.1790.

6. Osazuwa-Peters, N.; Simpson, M.C.; Zhao, L.; Boakye, E.A.; Olomukoro, S.I.; Deshields, T.; Loux, T.M.; Varvares, M.A.; Schootman, M. Suicide risk among cancer survivors: Head and neck versus other cancers. Cancer 2018, 124, 4072-4079, doi:10.1002/CNCR.31675.

7. Chitsike, L.; Duerksen-Hughes, P.J. Targeted Therapy as a Potential De-Escalation Strategy in Locally Advanced HPV-Associated Oropharyngeal Cancer: A Literature Review. Front. Oncol. 2021, 0, 3146, doi:10.3389/FONC.2021.730412.

8. Laban, S.; Gangkofner, D.S.; Holzinger, D.; Schroeder, L.; Eichmuller, S.B.; Zornig, I.; Jager, D.; Wichmann, G.; Dietz, A.; Broglie, M.A.; et al. Antibody responses to cancer antigens identify patients with a poor prognosis among HPV-positive and HPV-negative head and neck squamous cell carcinoma patients. Clin. Cancer Res. 2019, 25, 7405-7412, doi:10.1158/10780432.CCR-19-1490.

9. Gibbs, Z.A.; Whitehurst, A.W. Emerging Contributions of Cancer/Testis Antigens to Neoplastic Behaviors. Trends in Cancer 2018, 4, 701-712, doi:10.1016/j.trecan.2018.08.005.

10. Simpson, A.J.G.; Caballero, O.L.; Jungbluth, A.; Chen, Y.-T.; Old, L.J. Cancer/testis antigens, gametogenesis and cancer. Nat. Rev. Cancer 200558 2005, 5, 615-625, doi:10.1038/nrc1669.

11. Van Der Bruggen, P.; Traversari, C.; Chomez, P.; Lurquin, C.; De Plaen, E.; Van Den Eynde, B.; Knuth, A.; Boon, T. A gene encoding an antigen recognized by cytolytic T lymphocytes on a human melanoma. Science (80-. ). 1991, 254, 1643-1647, doi:10.1126/science.1840703.

12. Almeida, L.G.; Sakabe, N.J.; deOliveira, A.R.; Silva, M.C.C.; Mundstein, A.S.; Cohen, T.; Chen, Y.-T.; Chua, R.; Gurung, S.; Gnjatic, S.; et al. CTdatabase: a knowledge-base of highthroughput and curated data on cancer-testis antigens. Nucleic Acids Res. 2009, 37, D816, doi:10.1093/NAR/GKN673.

13. Boël, P.; Wildmann, C.; Sensi, M.L.; Brasseur, R.; Renauld, J.C.; Coulie, P.; Boon, T.; van der Bruggen, P. BAGE: a new gene encoding an antigen recognized on human melanomas by 
cytolytic T lymphocytes. Immunity 1995, 2, 167-175, doi:10.1016/S1074-7613(95)80053-0.

14. Van den Eynde, B.; Peeters, O.; De Backer, O.; Gaugler, B.; Lucas, S.; Boon, T. A new family of genes coding for an antigen recognized by autologous cytolytic $\mathrm{T}$ lymphocytes on a human melanoma. J. Exp. Med. 1995, 182, 689-698, doi:10.1084/JEM.182.3.689.

15. Sahin, U.; Türeci, O.; Schmitt, H.; Cochlovius, B.; Johannes, T.; Schmits, R.; Stenner, F.; Luo, G.; Schobert, I.; Pfreundschuh, M. Human neoplasms elicit multiple specific immune responses in the autologous host. Proc. Natl. Acad. Sci. 1995, 92, 11810-11813, doi:10.1073/PNAS.92.25.11810.

16. Türeci, Ö.; Sahin, U.; Zwick, C.; Koslowski, M.; Seitz, G.; Pfreundschuh, M. Identification of a meiosis-specific protein as a member of the class of cancer/testis antigens. Proc. Natl. Acad. Sci. 1998, 95, 5211-5216, doi:10.1073/PNAS.95.9.5211.

17. Chen, Y.-T.; Scanlan, M.J.; Sahin, U.; Türeci, Ö.; Gure, A.O.; Tsang, S.; Williamson, B.; Stockert, E.; Pfreundschuh, M.; Old, L.J. A testicular antigen aberrantly expressed in human cancers detected by autologous antibody screening. Proc. Natl. Acad. Sci. 1997, 94, 1914-1918, doi:10.1073/PNAS.94.5.1914.

18. Gibbs, Z.A.; Whitehurst, A.W. Emerging Contributions of Cancer/Testis Antigens to Neoplastic Behaviors. Trends in Cancer 2018, 4, 701-712, doi:10.1016/j.trecan.2018.08.005.

19. Hofmann, O.; Caballero, O.L.; Stevenson, B.J.; Chen, Y.-T.; Cohen, T.; Chua, R.; Maher, C.A.; Panji, S.; Schaefer, U.; Kruger, A.; et al. Genome-wide analysis of cancer/testis gene expression. Proc. Natl. Acad. Sci. 2008, 105, 20422-20427, doi:10.1073/PNAS.0810777105.

20. Wang, C.; Gu, Y.; Zhang, K.; Xie, K.; Zhu, M.; Dai, N.; Jiang, Y.; Guo, X.; Liu, M.; Dai, J.; et al. Systematic identification of genes with a cancer-testis expression pattern in 19 cancer types. Nat. Commun. 201671 2016, 7, 1-12, doi:10.1038/ncomms10499.

21. Stevenson, B.J.; Iseli, C.; Panji, S.; Zahn-Zabal, M.; Hide, W.; Old, L.J.; Simpson, A.J.; Jongeneel, C.V. Rapid evolution of cancer/testis genes on the X chromosome. BMC Genomics 200781 2007, 8, 1-11, doi:10.1186/1471-2164-8-129.

22. Whitehurst, A.W. Cause and Consequence of Cancer/Testis Antigen Activation in Cancer. Annu. Rev. Pharmacol. Toxicol. 2014, 54, 251-272, doi:10.1146/annurev-pharmtox-011112140326.

23. De Smet, C.; De Backer, O.; Faraoni, I.; Lurquin, C.; Brasseur, F.; Boon, T. The activation of human gene MAGE-1 in tumor cells is correlated with genome-wide demethylation. Proc. Natl. Acad. Sci. U. S. A. 1996, 93, 7149-7153, doi:10.1073/pnas.93.14.7149.

24. De Smet, C.; Lurquin, C.; Lethé, B.; Martelange, V.; Boon, T. DNA Methylation Is the Primary Silencing Mechanism for a Set of Germ Line- and Tumor-Specific Genes with a CpG-Rich Promoter. Mol. Cell. Biol. 1999, 19, 7327-7335, doi:10.1128/mcb.19.11.7327.

25. Koslowski, M.; Bell, C.; Seitz, G.; Lehr, H.A.; Roemer, K.; Müntefering, H.; Huber, C.; Sahin, U.; Türeci, Ö. Frequent nonrandom activation of germ-line genes in human cancer. Cancer Res. 2004, 64, 5988-5993, doi:10.1158/0008-5472.CAN-04-1187.

26. Wischnewski, F.; Pantel, K.; Schwarzenbach, H. Promoter Demethylation and Histone Acetylation Mediate Gene Expression of MAGE-A1,-A2,-A3, and-A12 in Human Cancer Cells. Mol Cancer Res 2006, 4, 339-388, doi:10.1158/1541-7786.MCR-05-0229.

27. Loukinov, D.I.; Pugacheva, E.; Vatolin, S.; Pack, S.D.; Moon, H.; Chernukhin, I.; Mannan, P.; Larsson, E.; Kanduri, C.; Vostrov, A.A.; et al. BORIS, a novel male germ-line-specific protein 
associated with epigenetic reprogramming events, shares the same 11-zinc-finger domain with CTCF, the insulator protein involved in reading imprinting marks in the soma. Proc. Natl. Acad. Sci. U. S. A. 2002, 99, 6806-6811, doi:10.1073/pnas.092123699.

28. Vatolin, S.; Abdullaev, Z.; Pack, S.D.; Flanagan, P.T.; Custer, M.; Loukinov, D.I.; Pugacheva, E.; Hong, J.A.; Morse, H.; Schrump, D.S.; et al. Conditional Expression of the CTCF-Paralogous Transcriptional Factor BORIS in Normal Cells Results in Demethylation and Derepression of MAGE-A1 and Reactivation of Other Cancer-Testis Genes. Cancer Res. 2005, 65, 7751-7762, doi:10.1158/0008-5472.CAN-05-0858.

29. Kang, Y.; Hong, J.A.; Chen, G.A.; Nguyen, D.M.; Schrump, D.S. Dynamic transcriptional regulatory complexes including BORIS, CTCF and Sp1 modulate NY-ESO-1 expression in lung cancer cells. Oncogene 2007, 26, 4394-4403, doi:10.1038/sj.onc.1210218.

30. Renaud, S.; Pugacheva, E.M.; Delgado, M.D.; Braunschweig, R.; Abdullaev, Z.; Loukinov, D.; Benhattar, J.; Lobanenkov, V. Expression of the CTCF-paralogous cancer-testis gene, brother of the regulator of imprinted sites (BORIS), is regulated by three alternative promoters modulated by CpG methylation and by CTCF and p53 transcription factors. Nucleic Acids Res. 2007, 35, 7372-7388, doi:10.1093/NAR/GKM896.

31. Kono, K.; Iinuma, H.; Akutsu, Y.; Tanaka, H.; Hayashi, N.; Uchikado, Y.; Noguchi, T.; Fujii, H.; Okinaka, K.; Fukushima, R.; et al. Multicenter, phase II clinical trial of cancer vaccination for advanced esophageal cancer with three peptides derived from novel cancer-testis antigens. J. Transl. Med. 2012, 10, doi:10.1186/1479-5876-10-141.

32. Kono, K.; Mizukami, Y.; Daigo, Y.; Takano, A.; Masuda, K.; Yoshida, K.; Tsunoda, T.; Kawaguchi, Y.; Nakamura, Y.; Fujii, H. Vaccination with multiple peptides derived from novel cancer-testis antigens can induce specific T-cell responses and clinical responses in advanced esophageal cancer. Cancer Sci. 2009, 100, 1502-1509, doi:10.1111/j.13497006.2009.01200.x.

33. Rapoport, A.P.; Stadtmauer, E.A.; Binder-Scholl, G.K.; Goloubeva, O.; Vogl, D.T.; Lacey, S.F.; Badros, A.Z.; Garfall, A.; Weiss, B.; Finklestein, J.; et al. NY-ESO-1-specific TCR-engineered T cells mediate sustained antigen-specific antitumor effects in myeloma. Nat. Med. 2015, 21, 914921, doi:10.1038/nm.3910.

34. Slingluff, C.L.; Zarour, H.M.; Tawbi, H.A.H.; Kirkwood, J.M.; Postow, M.A.; Friedlander, P.; Devoe, C.E.; Gaughan, E.M.; Mauldin, I.S.; Olson, W.C.; et al. A phase 1 study of NY-ESO-1 vaccine + anti-CTLA4 antibody Ipilimumab (IPI) in patients with unresectable or metastatic melanoma. Oncoimmunology 2021, 10, doi:10.1080/2162402X.2021.1898105.

35. Pollack, S.M.; Lu, H.; Gnjatic, S.; Somaiah, N.; O'Malley, R.B.; Jones, R.L.; Hsu, F.J; Ter Meulen, J. First-in-Human Treatment with a Dendritic Cell-Targeting Lentiviral Vectorexpressing NY-ESO-1, LV305, Induces Deep, Durable Response in Refractory Metastatic Synovial Sarcoma Patient. J. Immunother. 2017, 40, 302-306, doi:10.1097/CJI.0000000000000183.

36. Somaiah, N.; Block, M.S.; Kim, J.W.; Shapiro, G.I.; Do, K.T.; Hwu, P.; Eder, J.P.; Jones, R.L.; Lu, H.; Meulen, J.H. ter; et al. First-in-Class, First-in-Human Study Evaluating LV305, a DendriticCell Tropic Lentiviral Vector, in Sarcoma and Other Solid Tumors Expressing NY-ESO-1. Clin. Cancer Res. 2019, 25, 5808-5817, doi:10.1158/1078-0432.CCR-19-1025.

37. Hanahan, D.; Weinberg, R.A. Hallmarks of cancer: The next generation. Cell 2011, 144, 646674, doi:10.1016/j.cell.2011.02.013. 
38. Jay, A.; Reitz, D.; Namekawa, S.H.; Heyer, W.-D. Cancer testis antigens and genomic instability: More than immunology. DNA Repair (Amst). 2021, 108, 103214, doi:10.1016/J.DNAREP.2021.103214.

39. Maxfield, K.E.; Taus, P.J.; Corcoran, K.; Wooten, J.; MacIon, J.; Zhou, Y.; Borromeo, M.; Kollipara, R.K.; Yan, J.; Xie, Y.; et al. Comprehensive functional characterization of cancertestis antigens defines obligate participation in multiple hallmarks of cancer. Nat. Commun. 2015, 6, 1-15, doi:10.1038/ncomms9840.

40. Wen, M.; Ren, H.; Zhang, S.; Li, T.; Zhang, J.; Ren, P. CT45A1 promotes the metastasis of osteosarcoma cells in vitro and in vivo through $\beta$-catenin. Cell Death Dis. 2021, 12, 1-10, doi:10.1038/s41419-021-03935-x.

41. Zhao, X.; Huang, L.; Lu, Y.; Jiang, W.; Song, Y.; Qiu, B.; Tao, D.; Liu, Y.; Ma, Y. PIWIL2 interacting with IKK to regulate autophagy and apoptosis in esophageal squamous cell carcinoma. Cell Death Differ. 2021, 28, 1941-1954, doi:10.1038/s41418-020-00725-4.

42. Yang, B.; Wang, L.; Luo, X.; Chen, L.; Yang, Z.; Liu, L. SPAG6 silencing inhibits the growth of the malignant myeloid cell lines SKM-1 and K562 via activating p53 and caspase activationdependent apoptosis. Int. J. Oncol. 2015, 46, 649-656, doi:10.3892/IJO.2014.2768.

43. Cheng, C.C.; Wooten, J.; Gibbs, Z.; McGlynn, K.; Mishra, P.; Whitehurst, A.W. Sperm-specific cox6b2 enhances oxidative phosphorylation, proliferation, and survival in human lung adenocarcinoma. Elife 2020, 9, 1-56, doi:10.7554/ELIFE.58108.

44. Yang, X.; Potts, P.R. CSAG2 is a cancer-specific activator of SIRT1. EMBO Rep. 2020, 21, e50912, doi:10.15252/EMBR.202050912.

45. Lazar, I.; Fabre, B.; Feng, Y.; Khateb, A.; Turko, P.; Martinez Gomez, J.M.; Frederick, D.T.; Levesque, M.P.; Feld, L.; Zhang, G.; et al. SPANX control of lamin A/C modulates nuclear architecture and promotes melanoma growth. Mol. Cancer Res. 2020, 18, 1560-1573, doi:10.1158/1541-7786.MCR-20-0291.

46. Lin, J.; Ma, J.C.; Yang, J.; Yin, J.Y.; Chen, X.X.; Guo, H.; Wen, X.M.; Zhang, T.J.; Qian, W.; Qian, J.; et al. Arresting of miR-186 and releasing of H19 by DDX43 facilitate tumorigenesis and CML progression. Oncogene 2018, 37, 2432-2443, doi:10.1038/s41388-018-0146-y.

47. Wang, D.; Wang, J.; Ding, N.; Li, Y.; Yang, Y.; Fang, X.; Zhao, H. MAGE-A1 promotes melanoma proliferation and migration through C-JUN activation. Biochem. Biophys. Res. Commun. 2016, 473, 959-965, doi:10.1016/J.BBRC.2016.03.161.

48. Por, E.; Byun, H.J.; Lee, E.J.; Lim, J.H.; Jung, S.Y.; Park, I.; Kim, Y.M.; Jeoung, D. Il; Lee, H. The Cancer/Testis Antigen CAGE with Oncogenic Potential Stimulates Cell Proliferation by Upregulating Cyclins D1 and E in an AP-1- and E2F-dependent Manner. J. Biol. Chem. 2010, 285, 14475-14485, doi:10.1074/JBC.M109.084400.

49. Atanackovic, D.; Hildebrandt, Y.; Jadczak, A.; Cao, Y.; Luetkens, T.; Meyer, S.; Kobold, S.; Bartels, K.; Pabst, C.; Lajmi, N.; et al. Cancer-testis antigens MAGE-C1/CT7 and MAGE-A3 promote the survival of multiple myeloma cells. Haematologica 2010, 95, 785-793, doi:10.3324/HAEMATOL.2009.014464.

50. He, J.; Zhao, Y.; Zhao, E.; Wang, X.; Dong, Z.; Chen, Y.; Yang, L.; Cui, H. Cancer-testis specific gene OIP5: A downstream gene of E2F1 that promotes tumorigenesis and metastasis in glioblastoma by stabilizing E2F1 signaling. Neuro. Oncol. 2018, 20, 1173-1184, doi:10.1093/neuonc/noy037. 
51. Levine, A.J. P53: 800 Million Years of Evolution and 40 Years of Discovery. Nat. Rev. Cancer 2020, 20, 471-480, doi:10.1038/s41568-020-0262-1.

52. Marcar, L.; MacLaine, N.J.; Hupp, T.R.; Meek, D.W. Mage-A Cancer/Testis Antigens Inhibit p53 Function by Blocking Its Interaction with Chromatin. Cancer Res. 2010, 70, 10362-10370, doi:10.1158/0008-5472.CAN-10-1341.

53. Monte, M.; Simonatto, M.; Peche, L.Y.; Bublik, D.R.; Gobessi, S.; Pierotti, M.A.; Rodolfo, M.; Schneider, C. MAGE-A tumor antigens target p53 transactivation function through histone deacetylase recruitment and confer resistance to chemotherapeutic agents. Proc. Natl. Acad. Sci. 2006, 103, 11160-11165, doi:10.1073/PNAS.0510834103.

54. Brooks, C.L.; Gu, W. Ubiquitination, phosphorylation and acetylation: the molecular basis for p53 regulation. Curr. Opin. Cell Biol. 2003, 15, 164-171, doi:10.1016/S0955-0674(03)00003-6.

55. Kim, Y.; Park, H.; Park, D.; Lee, Y.S.; Choe, J.; Hahn, J.H.; Lee, H.; Kim, Y.M.; Jeoung, D. Cancer/Testis Antigen CAGE Exerts Negative Regulation on p53 Expression through HDAC2 and Confers Resistance to Anti-cancer Drugs. J. Biol. Chem. 2010, 285, 25957-25968, doi:10.1074/JBC.M109.095950.

56. Zijl, F. van; Krupitza, G.; Mikulits, W. Initial steps of metastasis: Cell invasion and endothelial transmigration. Mutat. Res. 2011, 728, 23, doi:10.1016/J.MRREV.2011.05.002.

57. Kim, Y.; Park, D.; Kim, H.; Choi, M.; Lee, H.; Lee, Y.S.; Choe, J.; Kim, Y.M.; Jeoung, D. MiR$200 \mathrm{~b}$ and cancer/testis antigen cage form a feedback loop to regulate the invasion and tumorigenic and angiogenic responses of a cancer cell line to microtubule-Targeting drugs. J. Biol. Chem. 2013, 288, 36502-36518, doi:10.1074/jbc.M113.502047.

58. Shuvalov, O.; Kizenko, A.; Petukhov, A.; Fedorova, O.; Daks, A.; Bottrill, A.; Snezhkina, A. V.; Kudryavtseva, A. V.; Barlev, N. SEMG1/2 augment energy metabolism of tumor cells. Cell Death Dis. 2020, 11, 1047, doi:10.1038/s41419-020-03251-w.

59. Dayton, T.L.; Jacks, T.; Heiden, M.G. Vander PKM2, cancer metabolism, and the road ahead. EMBO Rep. 2016, 17, 1721, doi:10.15252/EMBR.201643300.

60. Miao, P.; Sheng, S.; Sun, X.; Liu, J.; Huang, G. Lactate dehydrogenase a in cancer: A promising target for diagnosis and therapy. IUBMB Life 2013, 65, 904-910, doi:10.1002/IUB.1216.

61. Tacer, K.F.; Montoya, M.C.; Oatley, M.J.; Lord, T.; Oatley, J.M.; Klein, J.; Ravichandran, R.; Tillman, H.; Kim, M.S.; Connelly, J.P.; et al. MAGE cancer-testis antigens protect the mammalian germline under environmental stress. Sci. Adv. 2019, 5, doi:10.1126/SCIADV.AAV4832.

62. Qu, Q.; Zeng, F.; Liu, X.; Wang, Q.J.; Deng, F. Fatty acid oxidation and carnitine palmitoyltransferase I: Emerging therapeutic targets in cancer. Cell Death Dis. 2016, 7, e2226e2226, doi:10.1038/cddis.2016.132.

63. Watkins, J.; Weekes, D.; Shah, V.; Gazinska, P.; Joshi, S.; Sidhu, B.; Gillett, C.; Pinder, S.; Vanoli, F.; Jasin, M.; et al. Genomic Complexity Profiling Reveals That HORMAD1 Overexpression Contributes to Homologous Recombination Deficiency in Triple-Negative Breast Cancers. Cancer Discov. 2015, 5, 488-505, doi:10.1158/2159-8290.CD-14-1092.

64. Liu, K.; Wang, Y.; Zhu, Q.; Li, P.; Chen, J.; Tang, Z.; Shen, Y.; Cheng, X.; Lu, L.Y.; Liu, Y. Aberrantly expressed HORMAD1 disrupts nuclear localization of MCM8-MCM9 complex and compromises DNA mismatch repair in cancer cells. Cell Death Dis. 2020, 11, 519, doi:10.1038/s41419-020-2736-1. 
65. Gaugler, B.; Van den Eynde, B.; van der Bruggen, P.; Romero, P.; Gaforio, J.J.; De Plaen, E.; Lethé, B.; Brasseur, F.; Boon, T. Human gene MAGE-3 codes for an antigen recognized on a melanoma by autologous cytolytic T lymphocytes. J. Exp. Med. 1994, 179, 921-930, doi:10.1084/JEM.179.3.921.

66. Van den Eynde, B.; Peeters, O.; De Backer, O.; Gaugler, B.; Lucas, S.; Boon, T. A new family of genes coding for an antigen recognized by autologous cytolytic $\mathrm{T}$ lymphocytes on a human melanoma. J. Exp. Med. 1995, 182, 689-698, doi:10.1084/JEM.182.3.689.

67. Lethé, B.; Lucas, S.; Michaux, L.; De Smet, C.; Godelaine, D.; Serrano, A.; De Plaen, E.; Boon, T. LAGE-1, a new gene with tumor specificity. Int. J. Cancer 1998, 76, 903-908, doi:10.1002/(SICI)1097-0215(19980610)76:6<903::AID-IJC22>3.0.CO;2-1.

68. Figueiredo, D.L.A.; Mamede, R.C.M.; Spagnoli, G.C.; Silva, W.A.; Zago, M.; Neder, L.; Jungbluth, A.A.; Saggioro, F.P. High expression of cancer testis antigens MAGE-A, MAGEC1/CT7, MAGE-C2/CT10, NY-ESO-1, and gage in advanced squamous cell carcinoma of the larynx. Head Neck 2011, 33, 702-707, doi:10.1002/HED.21522.

69. Laban, S.; Giebel, G.; Klümper, N.; Schröck, A.; Doescher, J.; Spagnoli, G.; Thierauf, J.; Theodoraki, M.-N.; Remark, R.; Gnjatic, S.; et al. MAGE expression in head and neck squamous cell carcinoma primary tumors, lymph node metastases and respective recurrences-implications for immunotherapy. Oncotarget 2017, 8, 14719-14735, doi:10.18632/ONCOTARGET.14830.

70. Laban, S.; Atanackovic, D.; Luetkens, T.; Knecht, R.; Busch, C.-J.; Freytag, M.; Spagnoli, G.; Ritter, G.; Hoffmann, T.K.; Knuth, A.; et al. Simultaneous cytoplasmic and nuclear protein expression of melanoma antigen-A family and NY-ESO-1 cancer-testis antigens represents an independent marker for poor survival in head and neck cancer. Int. J. Cancer 2014, 135, 1142 1152, doi:10.1002/IJC.28752.

71. Eura, M.; Ogi, K.; Chikamatsu, K.; Lee, K.D.; Nakano, K.; Masuyama, K.; Itoh, K.; Ishikawa, T. Expression of the MAGE gene family in human head-and-neck squamous-cell carcinomas. Int. J. Cancer 1995, 64, 304-308, doi:10.1002/IJC.2910640504.

72. Kienstra, M.A.; Neel, H.B.; Strome, S.E.; Roche, P. Identification of NY-ESO-1, MAGE-1, and MAGE-3 in head and neck squamous cell carcinoma. Head Neck 2003, 25, 457-463, doi:10.1002/HED.10223.

73. Zamunér, F.T.; Karia, B.T.R.; Oliveira, C.Z. de; Santos, C.R. dos; Carvalho, A.L.; Vettore, A.L. A Comprehensive Expression Analysis of Cancer Testis Antigens in Head and Neck Squamous Cell Carcinoma Revels MAGEA3/6 as a Marker for Recurrence. Mol. Cancer Ther. 2015, 14, 828-834, doi:10.1158/1535-7163.MCT-14-0796.

74. Figueiredo, D.L.A.; Mamede, R.C.M.; Proto-Siqueira, R.; Neder, L.; Silva, W.A.; Zago, M.A. Expression of cancer testis antigens in head and neck squamous cell carcinomas. Head Neck 2006, 28, 614-619, doi:10.1002/HED.20380.

75. Glazer, C.A.; Smith, I.M.; Bhan, S.; Sun, W.; Chang, S.S.; Pattani, K.M.; Westra, W.; Khan, Z.; Califano, J.A. The Role of MAGEA2 in Head and Neck Cancer. Arch. Otolaryngol. Neck Surg. 2011, 137, 286-293, doi:10.1001/ARCHOTO.2011.2.

76. Gao, X.; Chen, G.; Cai, H.; Wang, X.; Song, K.; Liu, L.; Qiu, T.; He, Y. Aberrantly enhanced melanoma-associated antigen (MAGE)-A3 expression facilitates cervical cancer cell proliferation and metastasis via actuating Wnt signaling pathway. Biomed. Pharmacother. 2020, 
122, 109710, doi:10.1016/j.biopha.2019.109710.

77. Chen, X.; Wang, L.; Liu, J.; Huang, L.; Li, Y.; Gao, Q.; Shi, X.; Li, J.; Li, F.; Zhang, Z.; et al. Expression and prognostic relevance of MAGE-A3 and MAGE-C2 in non-small cell lung cancer. Oncol. Lett. 2017, 13, 1609-1618, doi:10.3892/ol.2017.5665.

78. Craig, A.J.; Garcia-Lezana, T.; de Galarreta, M.R.; Villacorta-Martin, C.; Kozlova, E.G.; Martins-Filho, S.N.; Felden, J. von; Ahsen, M.E.; Bresnahan, E.; Hernandez-Meza, G.; et al. Transcriptomic characterization of cancer-testis antigens identifies MAGEA3 as a driver of tumor progression in hepatocellular carcinoma. PLoS Genet. 2021, 17, e1009589, doi:10.1371/journal.pgen.1009589.

79. Atanackovic, D.; Blum, I.; Cao, Y.; Wenzel, S.; Bartels, K.; Faltz, C.; Hossfeld, D.K.; HegewischBecker, S.; Bokemeyer, C.; Leuwer, R. Expression of cancer-testis antigens as possible targets for antigen-specific immunotherapy in head and neck squamous cell carcinoma. Cancer Biol. Ther. 2006, 5, 1218-1225, doi:10.4161/cbt.5.9.3174.

80. Lee, A.K.; Potts, P.R. A Comprehensive Guide to the MAGE Family of Ubiquitin Ligases. J. Mol. Biol. 2017, 429, 1114-1142, doi:10.1016/J.JMB.2017.03.005.

81. Liu, W.; Cheng, S.; Asa, S.L.; Ezzat, S. The Melanoma-Associated Antigen A3 Mediates Fibronectin-Controlled Cancer Progression and Metastasis. Cancer Res. 2008, 68, 8104-8112, doi:10.1158/0008-5472.CAN-08-2132.

82. Pineda, C.T.; Ramanathan, S.; Fon Tacer, K.; Weon, J.L.; Potts, M.B.; Ou, Y.H.; White, M.A.; Potts, P.R. Degradation of AMPK by a Cancer-Specific Ubiquitin Ligase. Cell 2015, 160, 715728, doi:10.1016/J.CELL.2015.01.034.

83. Gao, Y.; Mutter-Rottmayer, E.; Greenwalt, A.M.; Goldfarb, D.; Yan, F.; Yang, Y.; MartinezChacin, R.C.; Pearce, K.H.; Tateishi, S.; Major, M.B.; et al. A neomorphic cancer cell-specific role of MAGE-A4 in trans-lesion synthesis. Nat. Commun. 2016, 7, 12105, doi:10.1038/ncomms12105.

84. Bhan, S.; Chuang, A.; Negi, S.S.; Glazer, C.A.; Califano, J.A. MAGEA4 induces growth in normal oral keratinocytes by inhibiting growth arrest and apoptosis. Oncol. Rep. 2012, 28, 1498-1502, doi:10.3892/OR.2012.1934.

85. Montoro, J.R.D.M.C.; Mamede, R.C.M.; Neder Serafini, L.; Saggioro, F.P.; Figueiredo, D.L.A.; Silva, W.A. Da; Jungbluth, A.A.; Spagnoli, G.C.; Zago, M.A. Expression of cancer-testis antigens MAGE-A4 and MAGE-C1 in oral squamous cell carcinoma. Head Neck 2012, 34, 11231128, doi:10.1002/hed.21880.

86. Iwamoto, O.; Nagao, Y.; Shichijo, S.; Eura, M.; Kameyama, T.; Itoh, K. Detection of MAGE-4 protein in sera of patients with head-and-neck squamous-cell carcinoma. Int. J. Cancer 1997, 70, 287-290, doi:10.1002/(SICI)1097-0215(19970127)70:3<287::AID-IJC7>3.0.CO;2-T.

87. Ishihara, M.; Kageyama, S.; Miyahara, Y.; Ishikawa, T.; Ueda, S.; Soga, N.; Naota, H.; Mukai, K.; Harada, N.; Ikeda, H.; et al. MAGE-A4, NY-ESO-1 and SAGE mRNA expression rates and co-expression relationships in solid tumours. BMC Cancer 2020, 20, 606, doi:10.1186/s12885020-07098-4.

88. Monji, M.; Senju, S.; Nakatsura, T.; Yamada, K.; Sawatsubashi, M.; Inokuchi, A.; Nishimura, Y. Head and neck cancer antigens recognized by the humoral immune system. Biochem. Biophys. Res. Commun. 2002, 294, 734-741, doi:10.1016/S0006-291X(02)00543-0.

89. Pan, S.J.; Ren, J.; Jiang, H.; Liu, W.; Hu, L.Y.; Pan, Y.X.; Sun, B.; Sun, Q.F.; Bian, L.G. MAGEA6 
promotes human glioma cell survival via targeting AMPK $\alpha 1$. Cancer Lett. 2018, 412, 21-29, doi:10.1016/j.canlet.2017.09.051.

90. Wei, Y.; Wang, Y.; Gong, J.; Rao, L.; Wu, Z.; Nie, T.; Shi, D.; Zhang, L. High expression of MAGE-A9 contributes to stemness and malignancy of human hepatocellular carcinoma. Int. J. Oncol. 2018, 52, 219-230, doi:10.3892/ijo.2017.4198.

91. Hartmann, S.; Zwick, L.; Maurus, K.; Fuchs, A.R.; Brands, R.C.; Seher, A.; Kübler, A.C.; MüllerRichter, U.D.A. Melanoma-associated antigen A11 reduces erlotinib and afatinib efficacy in head and neck cancer. J. Cranio-Maxillofacial Surg. 2018, 46, 492-497, doi:10.1016/J.JCMS.2017.12.014.

92. Jia, S.; Zhang, M.; Li, Y.; Zhang, L.; Dai, W. Mage-a11 expression predicts patient prognosis in head and neck squamous cell carcinoma. Cancer Manag. Res. 2020, 12, 1427-1435, doi:10.2147/CMAR.S237867.

93. Karia, B.T.R.; Zamuner, F.T.; Carlin, V.; de Oliveira, C.Z.; Carvalho, A.L.; Vettore, A.L. Expression and Prognostic Relevance of GAGE1 and XAGE1 Cancer/Testis Antigens in Head and Neck Squamous Cell Carcinoma. Curr. Mol. Med. 2018, 17, 707-717, doi:10.2174/1566524018666180322162145.

94. Oh, C.; Kim, H.R.; Oh, S.; Ko, J.Y.; Kim, Y.; Kang, K.; Yang, Y.; Kim, J.; Park, J.H.; Roe, J.S.; et al. Epigenetic upregulation of mage-a isoforms promotes breast cancer cell aggressiveness. Cancers (Basel). 2021, 13, 3176, doi:10.3390/cancers13133176.

95. Peche, L.Y.; Ladelfa, M.F.; Toledo, M.F.; Mano, M.; Laiseca, J.E.; Schneider, C.; Monte, M. Human MageB2 protein expression enhances E2F transcriptional activity, cell proliferation, and resistance to ribotoxic stress. J. Biol. Chem. 2015, 290, 29652-29662, doi:10.1074/jbc.M115.671982.

96. Pattani, K.M.; Soudry, E.; Glazer, C.A.; Ochs, M.F.; Wang, H.; Schussel, J.; Sun, W.; Hennessey, P.; Mydlarz, W.; Loyo, M.; et al. MAGEB2 is Activated by Promoter Demethylation in Head and Neck Squamous Cell Carcinoma. PLoS One 2012, 7, e45534, doi:10.1371/JOURNAL.PONE.0045534.

97. Piotti, K.C.; Scognamiglio, T.; Chiu, R.; Chen, Y.T. Expression of cancer/testis (CT) antigens in squamous cell carcinoma of the head and neck: Evaluation as markers of squamous dysplasia. Pathol. - Res. Pract. 2013, 209, 721-726, doi:10.1016/J.PRP.2013.08.004.

98. Hao, J.; Song, X.; Wang, J.; Guo, C.; Li, Y.; Li, B.; Zhang, Y.; Yin, Y. Cancer-testis antigen MAGE-C2 binds Rbx1 and inhibits ubiquitin ligase-mediated turnover of cyclin E. Oncotarget 2015, 6, 42028, doi:10.18632/ONCOTARGET.5973.

99. Song, X.; Hao, J.; Wang, J.; Guo, C.; Wang, Y.; He, Q.; Tang, H.; Qin, X.; Li, Y.; Zhang, Y.; et al. The cancer/testis antigen MAGEC2 promotes amoeboid invasion of tumor cells by enhancing STAT3 signaling. Oncogene 2017, 36, 1476-1486, doi:10.1038/onc.2016.314.

100. Cuffel, C.; Rivals, J.-P.; Zaugg, Y.; Salvi, S.; Seelentag, W.; Speiser, D.E.; Liénard, D.; Monnier, P.; Romero, P.; Bron, L.; et al. Pattern and clinical significance of cancer-testis gene expression in head and neck squamous cell carcinoma. Int. J. Cancer 2011, 128, 2625-2634, doi:10.1002/IJC.25607.

101. Lethé, B.; Lucas, S.; Michaux, L.; De Smet, C.; Godelaine, D.; Serrano, A.; De Plaen, E.; Boon, T. LAGE-1, a new gene with tumor specificity. Int. J. Cancer 1998, 76, 903-908, doi:10.1002/(SICI)1097-0215(19980610)76:6<903::AID-IJC22>3.0.CO;2-1. 
102. Cronwright, G.; Blanc, K. Le; Götherström, C.; Darcy, P.; Ehnman, M.; Brodin, B. Cancer/Testis Antigen Expression in Human Mesenchymal Stem Cells: Down-regulation of SSX Impairs Cell Migration and Matrix Metalloproteinase 2 Expression. Cancer Res. 2005, 65, 2207-2215, doi:10.1158/0008-5472.CAN-04-1882.

103. Chen, L.; Zhou, W.-B.; Zhao, Y.; Liu, X.-A.; Ding, Q.; Zha, X.-M.; Wang, S. Cancer/testis antigen SSX2 enhances invasiveness in MCF-7 cells by repressing ER $\alpha$ signaling. Int. J. Oncol. 2012, 40, 1986-1994, doi:10.3892/IJO.2012.1369.

104. Degrauwe, N.; Suvà, M.-L.; Janiszewska, M.; Riggi, N.; Stamenkovic, I. IMPs: an RNA-binding protein family that provides a link between stem cell maintenance in normal development and cancer. Genes Dev. 2016, 30, 2459-2474, doi:10.1101/GAD.287540.116.

105. Cilensek, Z.M.; Yehiely, F.; Kular, R.K.; Deiss, L.P. A member of the GAGE family of tumor antigens is an anti-apoptotic gene that confers resistance to Fas/CD95/APO-1, interferon- $\gamma$, taxol and $\gamma$-irradiation. Cancer Biol. Ther. 2002, 1, 380-387, doi:10.4161/cbt.1.4.11.

106. Götte, K.; Usener, D.; Riedel, F.; Hörmann, K.; Schadendorf, D.; Eichmüller, S. Tumorassociated antigens as possible targets for immune therapy in head and neck cancer: Comparative mRNA expression analysis of RAGE and GAGE genes. Acta Otolaryngol. 2002, 122, 546-552, doi:10.1080/00016480260092381.

107. Epping, M.T.; Wang, L.; Edel, M.J.; Carlée, L.; Hernandez, M.; Bernards, R. The Human Tumor Antigen PRAME Is a Dominant Repressor of Retinoic Acid Receptor Signaling. Cell 2005, 122, 835-847, doi:10.1016/J.CELL.2005.07.003.

108. Epping, M.T.; Bernards, R. A Causal Role for the Human Tumor Antigen Preferentially Expressed Antigen of Melanoma in Cancer. Cancer Res. 2006, 66, 10639-10642, doi:10.1158/0008-5472.CAN-06-2522.

109. Xu, B.; Jungbluth, A.A.; Frosina, D.; Alzumaili, B.; Aleynick, N.; Slodkowska, E.; Higgins, K.; Ho, A.; Morris, L.; Ghossein, R.; et al. The immune microenvironment and expression of PDL1, PD-1, PRAME and MHC I in salivary duct carcinoma. Histopathology 2019, 75, 672-682, doi:10.1111/HIS.13944.

110. Suzuki, I.; Yoshida, S.; Tabu, K.; Kusunoki, S.; Matsumura, Y.; Izumi, H.; Asanoma, K.; Yagi, H.; Onoyama, I.; Sonoda, K.; et al. YBX2 and cancer testis antigen 45 contribute to stemness, chemoresistance and a high degree of malignancy in human endometrial cancer. Sci. Rep. 2021, 11, 4220, doi:10.1038/s41598-021-83200-5.

111. Coscia, F.; Lengyel, E.; Duraiswamy, J.; Ashcroft, B.; Bassani-Sternberg, M.; Wierer, M.; Johnson, A.; Wroblewski, K.; Montag, A.; Yamada, S.D.; et al. Multi-level Proteomics Identifies CT45 as a Chemosensitivity Mediator and Immunotherapy Target in Ovarian Cancer. Cell 2018, 175, 159-170.e16, doi:10.1016/J.CELL.2018.08.065.

112. Usener, D.; Schadendorf, D.; Koch, J.; Dübel, S.; Eichmüller, S. cTAGE: A Cutaneous T Cell Lymphoma Associated Antigen Family with Tumor-Specific Splicing. J. Invest. Dermatol. 2003, 121, 198-206, doi:10.1046/J.1523-1747.2003.12318.X.

113. Gao, Q.; Xiang, S.; Wilson, K.; Madondo, M.; Stephens, A.; Plebanski, M. Sperm Protein 17 Expression by Murine Epithelial Ovarian Cancer Cells and Its Impact on Tumor Progression. Cancers (Basel). 2018, 10, 276, doi:10.3390/cancers10080276.

114. Li, F. qiu; Han, Y. ling; Liu, Q.; Wu, B.; Huang, W. bin; Zeng, S. yun Overexpression of human sperm protein 17 increases migration and decreases the chemosensitivity of human epithelial 
ovarian cancer cells. BMC Cancer 2009, 9, 323, doi:10.1186/1471-2407-9-323.

115. Schutt, C.A.; Mirandola, L.; Figueroa, J.A.; Nguyen, D.D.; Cordero, J.; Bumm, K.; Judson, B.L.; Chiriva-Internati, M.; Schutt, C.A.; Mirandola, L.; et al. The cancer-testis antigen, sperm protein 17, a new biomarker and immunological target in head and neck squamous cell carcinoma. Oncotarget 2017, 8, 100280-100287, doi:10.18632/ONCOTARGET.22213.

116. Chen, L.; Cai, S.; Wang, J. mei; Huai, Y. ying; Lu, P.H.; Chu, Q. BRDT promotes ovarian cancer cell growth. Cell Death Dis. 2020, 11, 1021, doi:10.1038/s41419-020-03225-y.

117. Wan, P.; Chen, Z.; Zhong, W.; Jiang, H.; Huang, Z.; Peng, D.; He, Q.; Chen, N. BRDT is a novel regulator of eIF4EBP1 in renal cell carcinoma. Oncol. Rep. 2020, 44, 2475-2486, doi:10.3892/OR.2020.7796.

118. Scanlan, M.J.; Altorki, N.K.; Gure, A.O.; Williamson, B.; Jungbluth, A.; Chen, Y.T.; Old, L.J. Expression of cancer-testis antigens in lung cancer: definition of bromodomain testis-specific gene (BRDT) as a new CT gene, CT9. Cancer Lett. 2000, 150, 155-164, doi:10.1016/S03043835(99)00385-7.

119. Han, Q.; Sun, M.L.; Liu, W.S.; Zhao, H.S.; Jiang, L.Y.; Yu, Z.J.; Wei, M.J. Upregulated expression of ACTL8 contributes to invasion and metastasis and indicates poor prognosis in colorectal cancer. Onco. Targets. Ther. 2019, 12, 1749-1763, doi:10.2147/OTT.S185858.

120. Li, B.; Zhu, J.; Meng, L. High expression of ACTL8 is poor prognosis and accelerates cell progression in head and neck squamous cell carcinoma. Mol. Med. Rep. 2019, 19, 877-884, doi:10.3892/MMR.2018.9716.

121. Chen, R.; Sheng, C.; Ma, R.; Zhang, L.; Yang, L.; Chen, Y. PLAC1 is an independent predictor of poor survival, and promotes cell proliferation and invasion in cervical cancer. Mol. Med. Rep. 2021, 24, 1-12, doi:10.3892/MMR.2021.12440.

122. Li, Y.; Chu, J.; Li, J.; Feng, W.; Yang, F.; Wang, Y.; Zhang, Y.; Sun, C.; Yang, M.; Vasilatos, S.N.; et al. Cancer/testis antigen-Plac1 promotes invasion and metastasis of breast cancer through Furin/NICD/PTEN signaling pathway. Mol. Oncol. 2018, 12, 1233-1248, doi:10.1002/18780261.12311.

123. Hayashi, R.; Nagato, T.; Kumai, T.; Ohara, K.; Ohara, M.; Ohkuri, T.; Hirata-Nozaki, Y.; Harabuchi, S.; Kosaka, A.; Nagata, M.; et al. Expression of placenta-specific 1 and its potential for eliciting anti-tumor helper T-cell responses in head and neck squamous cell carcinoma. Oncoimmunology 2021, 10, 1856545, doi:10.1080/2162402X.2020.1856545.

124. Witzleben, A. von; Wang, C.; Laban, S.; Savelyeva, N.; Ottensmeier, C.H. HNSCC: Tumour Antigens and Their Targeting by Immunotherapy. Cells 2020, 9, doi:10.3390/CELLS9092103.

125. Safety and Efficacy Study of GL-0817 (With Cyclophosphamide) for the Prevention of Recurrence of Squamous Cell Carcinoma of the Oral Cavity - Full Text View ClinicalTrials.gov Available online: https://clinicaltrials.gov/ct2/show/NCT02873819 (accessed on Sep 14, 2021).

126. Investigator Initiated Phase 1 Study of TBI-1201 - Full Text View - ClinicalTrials.gov Available online: https://clinicaltrials.gov/ct2/show/NCT02096614 (accessed on Sep 14, 2021).

127. Investigator Initiated Phase 1 Study of TBI-1301 - Full Text View - ClinicalTrials.gov Available online: https://clinicaltrials.gov/ct2/show/NCT02366546 (accessed on Sep 14, 2021).

128. To Evaluate the Efficacy of NY-ESO-1-specific T Cell Receptor Affinity Enhancing Specific T Cell in Solid Tumors - Full Text View - ClinicalTrials.gov Available online: 
https://clinicaltrials.gov/ct2/show/NCT03159585 (accessed on Sep 14, 2021).

129. Yoshitake, Y.; Fukuma, D.; Yuno, A.; Hirayama, M.; Nakayama, H.; Tanaka, T.; Nagata, M.; Takamune, Y.; Kawahara, K.; Nakagawa, Y.; et al. Phase II Clinical Trial of Multiple Peptide Vaccination for Advanced Head and Neck Cancer Patients Revealed Induction of Immune Responses and Improved OS. Clin. Cancer Res. 2015, 21, 312-321, doi:10.1158/1078-0432.CCR14-0202.

130. Harden, M.E.; Munger, K. Human papillomavirus molecular biology. Mutat. Res. - Rev. Mutat. Res. 2017, 772, 3-12, doi:10.1016/j.mrrev.2016.07.002.

131. Mesri, E.A.; Feitelson, M.A.; Munger, K. Human viral oncogenesis: A cancer hallmarks analysis. Cell Host Microbe 2014, 15, 266-282, doi:10.1016/j.chom.2014.02.011.

132. Vande Pol, S.B.; Klingelhutz, A.J. Papillomavirus E6 oncoproteins. Virology 2013, 445, 115-137, doi:10.1016/J.VIROL.2013.04.026.

133. Roman, A.; Munger, K. The papillomavirus E7 proteins. Virology 2013, 445, 138-168, doi:10.1016/J.VIROL.2013.04.013.

134. Chung, C.H.; Gillison, M.L. Human Papillomavirus in Head and Neck Cancer: Its Role in Pathogenesis and Clinical Implications. Clin. Cancer Res. 2009, 15, 6758-6762, doi:10.1158/10780432.CCR-09-0784.

135. Liu, C.; Mann, D.; Sinha, U.K.; Kokot, N.C. The molecular mechanisms of increased radiosensitivity of HPV-positive oropharyngeal squamous cell carcinoma (OPSCC): An extensive review. J. Otolaryngol. - Head Neck Surg. 2018, 47, 59, doi:10.1186/s40463-018-0302-y.

136. Gangkofner, D.S.; Holzinger, D.; Schroeder, L.; Eichmüller, S.B.; Zörnig, I.; Jäger, D.; Wichmann, G.; Dietz, A.; Broglie, M.A.; Herold-Mende, C.; et al. Patterns of antibody responses to nonviral cancer antigens in head and neck squamous cell carcinoma patients differ by human papillomavirus status. Int. J. Cancer 2019, 145, 3436-3444, doi:10.1002/IJC.32623.

137. Gleber-Netto, F.O.; Rao, X.; Guo, T.; Xi, Y.; Gao, M.; Shen, L.; Erikson, K.; Kalu, N.N.; Ren, S.; $\mathrm{Xu}, \mathrm{G}$; et al. Variations in HPV function are associated with survival in squamous cell carcinoma. JCI Insight 2019, 4, doi:10.1172/JCI.INSIGHT.124762.

138. Mehanna, H.; Rischin, D.; Wong, S.J.; Gregoire, V.; Ferris, R.; Waldron, J.; Le, Q.T.; Forster, M.; Gillison, M.; Laskar, S.; et al. De-escalation after DE-ESCALATE and RTOG 1016: A Head and Neck Cancer InterGroup framework for future de-escalation studies. J. Clin. Oncol. 2020, 38, 2552-2557, doi:10.1200/JCO.20.00056.

139. Slebos, R.J.C.; Yi, Y.; Ely, K.; Carter, J.; Evjen, A.; Zhang, X.; Shyr, Y.; Murphy, B.M.; Cmelak, A.J.; Burkey, B.B.; et al. Gene Expression Differences Associated with Human Papillomavirus Status in Head and Neck Squamous Cell Carcinoma. Clin. Cancer Res. 2006, 12, 701-709, doi:10.1158/1078-0432.CCR-05-2017.

140. Pyeon, D.; Newton, M.A.; Lambert, P.F.; Boon, J.A. den; Sengupta, S.; Marsit, C.J.; Woodworth, C.D.; Connor, J.P.; Haugen, T.H.; Smith, E.M.; et al. Fundamental Differences in Cell Cycle Deregulation in Human Papillomavirus-Positive and Human PapillomavirusNegative Head/Neck and Cervical Cancers. Cancer Res. 2007, 67, 4605-4619, doi:10.1158/00085472.CAN-06-3619.

141. Martinez, I.; Wang, J.; Hobson, K.F.; Ferris, R.L.; Khan, S.A. Identification of differentially expressed genes in HPV-positive and HPV-negative oropharyngeal squamous cell 
carcinomas. Eur. J. Cancer 2007, 43, 415-432, doi:10.1016/J.EJCA.2006.09.001.

142. Schlecht, N.; Burk, R.; Adrien, L.; Dunne, A.; Kawachi, N.; Sarta, C.; Chen, Q.; BrandweinGensler, M.; Prystowsky, M.; Childs, G.; et al. Gene expression profiles in HPV-infected head and neck cancer. J. Pathol. 2007, 213, 283-293, doi:10.1002/PATH.2227.

143. Masterson, L.; Sorgeloos, F.; Winder, D.; Lechner, M.; Marker, A.; Malhotra, S.; Sudhoff, H.; Jani, P.; Goon, P.; Sterling, J. Deregulation of SYCP2 predicts early stage human papillomavirus-positive oropharyngeal carcinoma: A prospective whole transcriptome analysis. Cancer Sci. 2015, 106, 1568-1575, doi:10.1111/CAS.12809.

144. Tian, G.; Fu, Y.; Zhang, D.; Li, J.; Zhang, Z.; Yang, X. Identification of four key prognostic genes and three potential drugs in human papillomavirus negative head and neck squamous cell carcinoma. Cancer Cell Int. 2021, 21, 167, doi:10.1186/s12935-021-01863-6.

145. Zhang, Y.; Koneva, L.A.; Virani, S.; Arthur, A.E.; Virani, A.; Hall, P.B.; Warden, C.D.; Carey, T.E.; Chepeha, D.B.; Prince, M.E.; et al. Subtypes of HPV-positive head and neck cancers are associated with HPV characteristics, copy number alterations, PIK3CA mutation, and pathway signatures. Clin. Cancer Res. 2016, 22, 4735, doi:10.1158/1078-0432.CCR-16-0323.

146. Gerton, J.L.; Hawley, R.S. Homologous chromosome interactions in meiosis: Diversity amidst conservation. Nat. Rev. Genet. 2005, 6, 477-487, doi:10.1038/nrg1614.

147. Hosoya, N.; Miyagawa, K. Synaptonemal complex proteins modulate the level of genome integrity in cancers. Cancer Sci. 2021, 112, 989, doi:10.1111/CAS.14791.

148. Page, S.L.; Hawley, R.S. The genetics and molecular biology of the synaptonemal complex. Annu. Rev. Cell Dev. Biol. 2004, 20, 525-558, doi:10.1146/annurev.cellbio.19.111301.155141.

149. Yang, F.; Fuente, R.D. La; Leu, N.A.; Baumann, C.; McLaughlin, K.J.; Wang, P.J. Mouse SYCP2 is required for synaptonemal complex assembly and chromosomal synapsis during male meiosis. J. Cell Biol. 2006, 173, 497-507, doi:10.1083/JCB.200603063.

150. Pelttari, J.; Hoja, M.-R.; Yuan, L.; Liu, J.-G.; Brundell, E.; Moens, P.; Santucci-Darmanin, S.; Jessberger, R.; Barbero, J.L.; Heyting, C.; et al. A Meiotic Chromosomal Core Consisting of Cohesin Complex Proteins Recruits DNA Recombination Proteins and Promotes Synapsis in the Absence of an Axial Element in Mammalian Meiotic Cells. Mol. Cell. Biol. 2001, 21, 56675677, doi:10.1128/MCB.21.16.5667-5677.2001.

151. Offenberg, H.H.; Schalk, J.A.C.; Meuwissen, R.L.J.; van Aalderen, M.; Kester, H.A.; Dietrich, A.J.J.; Heyting, C. SCP2: A major protein component of the axial elements of synaptonemal complexes of the rat. Nucleic Acids Res. 1998, 26, 2572-2579, doi:10.1093/NAR/26.11.2572.

152. Takemoto, K.; Imai, Y.; Saito, K.; Kawasaki, T.; Carlton, P.M.; Ishiguro, K.; Sakai, N. Sycp2 is essential for synaptonemal complex assembly, early meiotic recombination and homologous pairing in zebrafish spermatocytes. PLOS Genet. 2020, 16, e1008640, doi:10.1371/JOURNAL.PGEN.1008640.

153. Espinosa, A.M.; Alfaro, A.; Roman-Basaure, E.; Guardado-Estrada, M.; Palma, Í.; Serralde, C.; Medina, I.; Juárez, E.; Bermúdez, M.; Márquez, E.; et al. Mitosis Is a Source of Potential Markers for Screening and Survival and Therapeutic Targets in Cervical Cancer. PLoS One 2013, 8, doi:10.1371/journal.pone.0055975.

154. Li, Z.; Chen, J.; Zhao, S.; Li, Y.; Zhou, J.; Liang, J.; Tang, H. Discovery and validation of novel biomarkers for detection of cervical cancer. Cancer Med. 2021, 10, 2063-2074, doi:10.1002/CAM4.3799. 
155. Hosoya, N.; Okajima, M.; Kinomura, A.; Fujii, Y.; Hiyama, T.; Sun, J.; Tashiro, S.; Miyagawa, K. Synaptonemal complex protein SYCP3 impairs mitotic recombination by interfering with BRCA2. EMBO Rep. 2012, 13, 44-51, doi:10.1038/EMBOR.2011.221.

156. Duensing, S.; Münger, K. The human papillomavirus type 16 E6 and E7 oncoproteins independently induce numerical and structural chromosome instability. Cancer Res. 2002, 62, 7075-7082.

157. Duensing, S.; Münger, K. Mechanisms of genomic instability in human cancer: Insights from studies with human papillomavirus oncoproteins. Int. J. Cancer 2004, 109, 157-162, doi:10.1002/IJC.11691.

158. Mahgoub, M.; Paiano, J.; Bruno, M.; Wu, W.; Pathuri, S.; Zhang, X.; Ralls, S.; Cheng, X.; Nussenzweig, A.; Macfarlan, T. Dual histone methyl reader zcwpw1 facilitates repair of meiotic double strand breaks in male mice. Elife 2020, 9, doi:10.7554/ELIFE.53360.

159. Huang, T.; Yuan, S.; Gao, L.; Li, M.; Yu, X.; Zhang, J.; Yin, Y.; Liu, C.; Zhang, C.; Lu, G.; et al. The histone modification reader zcwpw1 links histone methylation to prdm9-induced double strand break repair. Elife 2020, 9, 1-48, doi:10.7554/ELIFE.53459.

160. Borde, V.; Robine, N.; Lin, W.; Bonfils, S.; Géli, V.; Nicolas, A. Histone H3 lysine 4 trimethylation marks meiotic recombination initiation sites. EMBO J. 2009, 28, 99-111, doi:10.1038/EMBOJ.2008.257.

161. Powers, N.R.; Parvanov, E.D.; Baker, C.L.; Walker, M.; Petkov, P.M.; Paigen, K. The Meiotic Recombination Activator PRDM9 Trimethylates Both H3K36 and H3K4 at Recombination Hotspots In Vivo. PLOS Genet. 2016, 12, e1006146, doi:10.1371/JOURNAL.PGEN.1006146.

162. Eram, M.S.; Bustos, S.P.; Lima-Fernandes, E.; Siarheyeva, A.; Senisterra, G.; Hajian, T.; Chau, I.; Duan, S.; Wu, H.; Dombrovski, L.; et al. Trimethylation of Histone H3 Lysine 36 by Human Methyltransferase PRDM9 Protein. J. Biol. Chem. 2014, 289, 12177-12188, doi:10.1074/JBC.M113.523183.

163. Wells, D.; Bitoun, E.; Moralli, D.; Zhang, G.; Hinch, A.G.; Jankowska, J.; Donnelly, P.; Green, C.; Myers, S.R. ZCWPW1 is recruited to recombination hotspots by PRDM9, and is essential for meiotic double strand break repair. Elife 2020, 9, 1-38, doi:10.7554/ELIFE.53392.

164. Li, M.; Huang, T.; Li, M.J.; Zhang, C.X.; Yu, X.C.; Yin, Y.Y.; Liu, C.; Wang, X.; Feng, H.W.; Zhang, T.; et al. The histone modification reader ZCWPW1 is required for meiosis prophase I in male but not in female mice. Sci. Adv. 2019, 5, doi:10.1126/SCIADV.AAX1101.

165. Hyun, K.; Jeon, J.; Park, K.; Kim, J. Writing, erasing and reading histone lysine methylations. Exp. Mol. Med. 2017, 49, e324-e324, doi:10.1038/emm.2017.11.

166. Chi, P.; Allis, C.D.; Wang, G.G. Covalent histone modifications-miswritten, misinterpreted and mis-erased in human cancers. Nat. Rev. Cancer 2010, 10, 457-469, doi:10.1038/nrc2876.

167. Parry, L.; Clarke, A.R. The Roles of the Methyl-CpG Binding Proteins in Cancer. Genes Cancer 2011, 2, 618, doi:10.1177/1947601911418499.

168. Pointud, J.-C.; Mengus, G.; Brancorsini, S.; Monaco, L.; Parvinen, M.; Sassone-Corsi, P.; Davidson, I. The intracellular localisation of TAF7L, a paralogue of transcription factor TFIID subunit TAF7, is developmentally regulated during male germ-cell differentiation. J. Cell Sci. 2003, 116, 1847-1858, doi:10.1242/JCS.00391.

169. Cheng, Y.; Buffone, M.G.; Kouadio, M.; Goodheart, M.; Page, D.C.; Gerton, G.L.; Davidson, I.; Wang, P.J. Abnormal Sperm in Mice Lacking the Taf7l Gene . Mol. Cell. Biol. 2007, 27, 2582- 
27 of 29

2589, doi:10.1128/MCB.01722-06.

170. Zhou, H.; Grubisic, I.; Zheng, K.; He, Y.; Wang, P.J.; Kaplan, T.; Tjian, R. Taf7l cooperates with Trf2 to regulate spermiogenesis. Proc. Natl. Acad. Sci. 2013, 110, 16886-16891, doi:10.1073/PNAS.1317034110.

171. Kodama, M.; Shimura, H.; Tien, J.C.; Newberg, J.Y.; Kodama, T.; Wei, Z.; Rangel, R.; Yoshihara, K.; Kuruma, A.; Nakae, A.; et al. Sleeping Beauty transposon mutagenesis identifies genes driving the initiation and metastasis of uterine leiomyosarcoma. Cancer Res. 2021, canres.0356.2021, doi:10.1158/0008-5472.can-21-0356.

172. Zhou, H.; Kaplan, T.; Li, Y.; Grubisic, I.; Zhang, Z.; Wang, P.J.; Eisen, M.B.; Tjian, R. Dual functions of TAF7L in adipocyte differentiation. Elife 2013, 2013, doi:10.7554/ELIFE.00170.

173. Zhou, H.; Wan, B.; Grubisic, I.; Kaplan, T.; Tjian, R. TAF7L modulates brown adipose tissue formation. Elife 2014, 2014, doi:10.7554/ELIFE.02811.

174. Prieto, I.; Suja, J.A.; Pezzi, N.; Kremer, L.; Martínez-A., C.; Rufas, J.S.; Barbero, J.L. Mammalian STAG3 is a cohesin specific to sister chromatid arms in meiosis I. Nat. Cell Biol. 2001, 3, 761766, doi:10.1038/35087082.

175. Losada, A. Cohesin in cancer: Chromosome segregation and beyond. Nat. Rev. Cancer 2014, 14, 389-393, doi:10.1038/nrc3743.

176. Beverley, R.; Snook, M.L.; Brieño-Enríquez, M.A. Meiotic Cohesin and Variants Associated With Human Reproductive Aging and Disease. Front. Cell Dev. Biol. 2021, 0, 2119, doi:10.3389/FCELL.2021.710033.

177. Llano, E.; Gomez-H, L.; García-Tuñón, I.; Sánchez-Martín, M.; Caburet, S.; Barbero, J.L.; Schimenti, J.C.; Veitia, R.A.; Pendas, A.M. STAG3 is a strong candidate gene for male infertility. Hum. Mol. Genet. 2014, 23, 3421-3431, doi:10.1093/HMG/DDU051.

178. Winters, T.; McNicoll, F.; Jessberger, R. Meiotic cohesin STAG3 is required for chromosome axis formation and sister chromatid cohesion. EMBO J. 2014, 33, 1256-1270, doi:10.1002/EMBJ.201387330.

179. Fukuda, T.; Fukuda, N.; Agostinho, A.; Hernández-Hernández, A.; Kouznetsova, A.; Höög, C. STAG3-mediated stabilization of REC8 cohesin complexes promotes chromosome synapsis during meiosis. EMBO J. 2014, 33, 1243-1255, doi:10.1002/EMBJ.201387329.

180. Hopkins, J.; Hwang, G.; Jacob, J.; Sapp, N.; Bedigian, R.; Oka, K.; Overbeek, P.; Murray, S.; Jordan, P.W. Meiosis-Specific Cohesin Component, Stag3 Is Essential for Maintaining Centromere Chromatid Cohesion, and Required for DNA Repair and Synapsis between Homologous Chromosomes. PLOS Genet. 2014, 10, e1004413, doi:10.1371/JOURNAL.PGEN.1004413.

181. Pereira, C.; Smolka, M.B.; Weiss, R.S.; Brieño-Enríquez, M.A. ATR signaling in mammalian meiosis: From upstream scaffolds to downstream signaling. Environ. Mol. Mutagen. 2020, 61, 752-766, doi:10.1002/EM.22401.

182. Bhattacharyya, T.; Walker, M.; Powers, N.R.; Brunton, C.; Fine, A.D.; Petkov, P.M.; Handel, M.A. Prdm9 and Meiotic Cohesin Proteins Cooperatively Promote DNA Double-Strand Break Formation in Mammalian Spermatocytes. Curr. Biol. 2019, 29, 1002-1018.e7, doi:10.1016/J.CUB.2019.02.007.

183. Storre, J.; Schäfer, A.; Reichert, N.; Barbero, J.L.; Hauser, S.; Eilers, M.; Gaubatz, S. Silencing of the Meiotic Genes SMC1 $\beta$ and STAG3 in Somatic Cells by E2F6. J. Biol. Chem. 2005, 280, 41380- 
28 of 29

41386, doi:10.1074/JBC.M506797200.

184. Stielow, B.; Finkernagel, F.; Stiewe, T.; Nist, A.; Suske, G. MGA, L3MBTL2 and E2F6 determine genomic binding of the non-canonical Polycomb repressive complex PRC1.6. PLOS Genet. 2018, 14, e1007193, doi:10.1371/JOURNAL.PGEN.1007193.

185. McLaughlin-Drubin, M.E.; Huh, K.-W.; Münger, K. Human Papillomavirus Type 16 E7 Oncoprotein Associates with E2F6. J. Virol. 2008, 82, 8695-8705, doi:10.1128/JVI.00579-08.

186. Shen, C.H.; Kim, S.H.; Trousil, S.; Frederick, D.T.; Piris, A.; Yuan, P.; Cai, L.; Gu, L.; Li, M.; Lee, J.H.; et al. Loss of cohesin complex components STAG2 or STAG3 confers resistance to BRAF inhibition in melanoma. Nat. Med. 2016, 22, 1056-1061, doi:10.1038/nm.4155.

187. Strunnikov, A. Cohesin complexes with a potential to link mammalian meiosis to cancer. Cell Regen. 2013, 2, 2:4, doi:10.1186/2045-9769-2-4.

188. Sasaki, M.; Miyoshi, N.; Fujino, S.; Saso, K.; Ogino, T.; Takahashi, H.; Uemura, M.; Yamamoto, H.; Matsuda, C.; Yasui, M.; et al. The meiosis-specific cohesin component stromal antigen 3 promotes cell migration and chemotherapeutic resistance in colorectal cancer. Cancer Lett. 2021, 497, 112-122, doi:10.1016/J.CANLET.2020.10.006.

189. Waldman, T. Emerging themes in cohesin cancer biology. Nat. Rev. Cancer 2020, 20, 504-515, doi:10.1038/s41568-020-0270-1.

190. Tirode, F.; Surdez, D.; Ma, X.; Parker, M.; Deley, M.C. Le; Bahrami, A.; Zhang, Z.; Lapouble, E.; Grossetête-Lalami, S.; Rusch, M.; et al. Genomic Landscape of Ewing Sarcoma Defines an Aggressive Subtype with Co-Association of STAG2 and TP53 Mutations. Cancer Discov. 2014, 4, 1342-1353, doi:10.1158/2159-8290.CD-14-0622.

191. Solomon, D.A.; Kim, T.; Diaz-Martinez, L.A.; Fair, J.; Elkahloun, A.G.; Harris, B.T.; Toretsky, J.A.; Rosenberg, S.A.; Shukla, N.; Ladanyi, M.; et al. Mutational inactivation of STAG2 causes aneuploidy in human cancer. Science (80-. ). 2011, 333, 1039-1043, doi:10.1126/SCIENCE.1203619.

192. Barber, T.D.; McManus, K.; Yuen, K.W.Y.; Reis, M.; Parmigiani, G.; Shen, D.; Barrett, I.; Nouhi, Y.; Spencer, F.; Markowitz, S.; et al. Chromatid cohesion defects may underlie chromosome instability in human colorectal cancers. Proc. Natl. Acad. Sci. 2008, 105, 3443-3448, doi:10.1073/PNAS.0712384105.

193. Guo, G.; Sun, X.; Chen, C.; Wu, S.; Huang, P.; Li, Z.; Dean, M.; Huang, Y.; Jia, W.; Zhou, Q.; et al. Whole-genome and whole-exome sequencing of bladder cancer identifies frequent alterations in genes involved in sister chromatid cohesion and segregation. Nat. Genet. 2013, 45, 1459-1463, doi:10.1038/ng.2798.

194. Balbás-Martínez, C.; Sagrera, A.; Carrillo-De-Santa-Pau, E.; Earl, J.; Márquez, M.; Vazquez, M.; Lapi, E.; Castro-Giner, F.; Beltran, S.; Bayés, M.; et al. Recurrent inactivation of STAG2 in bladder cancer is not associated with aneuploidy. Nat. Genet. 2013, 45, 1464-1469, doi:10.1038/ng.2799.

195. Kon, A.; Shih, L.Y.; Minamino, M.; Sanada, M.; Shiraishi, Y.; Nagata, Y.; Yoshida, K.; Okuno, Y.; Bando, M.; Nakato, R.; et al. Recurrent mutations in multiple components of the cohesin complex in myeloid neoplasms. Nat. Genet. 2013, 45, 1232-1237, doi:10.1038/ng.2731.

196. Rhodes, J.M.; McEwan, M.; Horsfield, J.A. Gene Regulation by Cohesin in Cancer: Is the Ring an Unexpected Party to Proliferation? Mol. Cancer Res. 2011, 9, 1587-1607, doi:10.1158/15417786.MCR-11-0382. 
29 of 29 